\title{
ANELÍDEOS POLIQUETOS DA COSTA BRASILEIRA. 5. PISIONIDAE, CHRYSOPETALIDAE, AMPHINOMIDAE E EUPHROSINIDAE
}

\author{
A. Cecilia Z. Amaral ${ }^{1}$ \\ Edmundo F. Nonato ${ }^{2}$
}

\begin{abstract}
Polychaete from Brazilian coast. 5. Pisionidae, ChrysopetaLIDAE, AMPHINOMIDAE AND EuphrosinidaE. This is the fifth fascicle of the series and deals with the polychaete families Psionidae, Chrysoptelidae, Amphinomidae e Euphrosinidae which are represented in the Brazilian coast respectively by 1, 5, 9 and 2 species. The specimens of all the species examined are deposited in the Collection of the Departamento de Zoologia, Instituto de Biologia of the Universidade Estadual de Campinas (UNICAMP), Campinas, São Paulo.

KEY WORDS. Pisionidae, Chrysopetalidae, Amphinomidae, Euphrosinidae
\end{abstract}

\section{CONTEÚDO}

INTRODUÇÃO . . . . . . . . . . . . . . . . . . . . . . . . . . 362

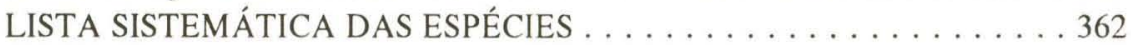

PISIONIDAE . . . . . . . . . . . . . . . . . . . . . . 363

Pisionidens Aiyar \& Alikunhi, 1943 . . . . . . . . . . . . . 363

CHRYSOPETALIDAE . . . . . . . . . . . . . . . . . . . . . . 364

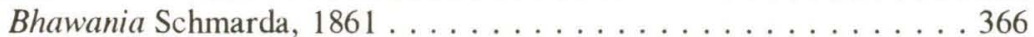

Chrysopetalum Ehlers, 1864 . . . . . . . . . . . . . . . . 369

Paleanotus Schamarda, $1861 \ldots \ldots$. . . . . . . . . . . 370

AMPHINOMIDAE . . . . . . . . . . . . . . . . . . . . . . . . . 370

Amphinome Bruguières, $1789 \ldots \ldots \ldots \ldots \ldots$. . . . . . . . 371

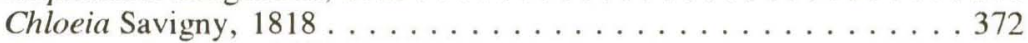

Eurythoe Kinberg, $1857 \ldots \ldots \ldots \ldots$. . . . . . . . . . . 374

Hermodice Kinberg, 1857 . . . . . . . . . . . . . . . . . . 376

Hypponoe Audouin \& Milne-Edwards, $1830 \ldots \ldots$. . . . . . 378

Notopygos Grube, $1855 \ldots \ldots \ldots \ldots$. . . . . . . . . . . 379

Paramphinome Sars, 1869 . . . . . . . . . . . . . . . 379

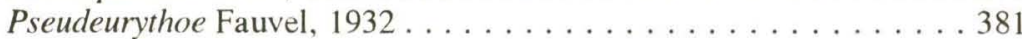

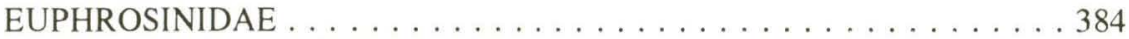

Euphrosine Savigny, $1818 \ldots \ldots \ldots \ldots \ldots \ldots \ldots$

REFERÊNCIAS BIBLIOGRÁFICAS . . . . . . . . . . . . . . . . 387

1) Departamento de Zoologia. Instituto de Biologia, Universidade Estadual de Campinas, Caixa Postal 6109, 13083-970 Campinas, São Paulo, Brasil.

2) Instituto Oceanográfico, Universidade de São Paulo, Caixa Postal 9075, 01065-970 São Paulo, São Paulo, Brasil. 
Dando continuidade à série dedicada aos anelídeos poliquetos da costa brasileira, foi elaborado este quinto fascículo que inclue as famílias PISIONIDAE, ChrysopetalidaE, AmphinomidaE e EUPHROSINIDAE.

As famílias Chrysopetalidae, Amphinomidae e Euphrosinidae são comumente incluídas entre as mais primitivas dos anelideos poliquetos. Os Anfinomídeos e Eufrosinideos estão intimamente relacionados entre si e são por alguns autores reunidos em uma única família.

DAY (1967) e ORENSANZ (1972) incluíram os Chrysopetalidae na família Palmyridae. FAUlCHALD (1977a) reune na superfamília CHRYSOPETALACEA as famílias Chrysopetalidae e Palmyridae, esta última com apenas um gênero descrito (Palmyra, não referido para o Brasil). As duas famílias são caracterizadas por notopódios providos de páleas, dispostas em fileiras transversais sobre o dorso, tendo como diferença básica o número de antenas.

Os Chrysopetalidae aproximam-se também dos Euphrosinidae pela posição semelhante das cerdas dorsais e pelas características das estruturas do prostômio. ORENSANZ (1972) sugere o gênero Palmyreuphrosine como intermediário entre as duas famílias.

Para a costa brasileira são referidas dezessete espécies; das quais uma de Pisionidae, cinco de Chrysopetalidae, nove de Amphinomidae e duas de Euphrosinidae.

Exemplares das espécies aqui descritas estão depositados na Coleção Annelida Polychaeta do Departamento de Zoologia, Instituto de Biologia da Universidade Estadual de Campinas, Campinas (São Paulo).

\section{LISTA SISTEMÁTICA DAS ESPÉCIES}

\section{PISIONIDAE}

Pisionidens indica (Aiyar \& Alikunhi, 1940)

\section{CHRYSOPETALIDAE}

Bhawania brunnea Morgado \& Amaral, 1981

Bhawania obscura (Grube, 1868)

Bhawania goodei Webster, 1884

Chrysopetalum occidentale Johnson, 1897

Paleanotus chrysolepis Schamarda, 1861

AMPHINOMIDAE

Amphinome rostrata (Pallas, 1776)

Chloeia viridis Schmarda, 1861

Eurythoe complanata (Pallas, 1776)

Hermodice carunculata (Pallas, 1776)

Hypponoe gaudichaudi Audouin \& Milne-Edwards, 1930

Hipponoe gaudichaudi agulhana Day, 1967

Notopygos crinita Grube, 1855

Paramphinome besnardii Temperini, 1981

Pseudeurythoe ambigua Fauvel, 1932

\section{EUPHROSINIDAE}

Euphrosine aurantiaca Johnson, 1897

Euphrosine triloba Ehlers, 1887 


\section{PISIONIDAE Southern, 1914}

As espécies incluídas nesta família tem formas delicadas, não ultrapassando $25 \mathrm{~mm}$ de comprimento.

Corpo delgado, filiforme, com segmentos numerosos. Prostômio bem desenvolvido (gênero Pisionidens) ou reduzido e inconspícuo (gêneros Pisione e Pisionella). Peristômio com dois pares de cirros tentaculares, acompanhados ou não por um par de acículos dirigidos para a frente. Faringe eversível com maxilas quitinosas. Parapódios unirremes, dotados ou não de cerdas; estas, quando presentes, são simples ou compostas. Papilas genitais geralmente conspícuas. Pigídio com um par de cirros anais.

A família Pisionidae inclui os gêneros: Anoplosione Laubier, 1967; Pisione Grube, 1857; Pisionella Hartman, 1939; e Pisionidens Aiyar \& Alikunhi, 1943. Até o presente, somente o gênero Pisionidens foi referido para o Brasil.

Os pisionideos são vermes carnívoros, bem adaptados ao ambiente da zona entremarés, ocorrendo principalmente em fundos de areia.

Discussão. LEVINSEN (1887) criou a família Pisionidae para acolher o gênero Pisione Grube, 1857; porém o autor não a fez acompanhar de uma descrição. FAUVEL (1923) e DAY (1967) referem a familia Pisionidae como sendo de Levinsen (1887). EHLERS (1901) dá uma nova diagnose de Pisione, completada por uma minuciosa discussão e considera que ambas se aplicam também à família que, até então, continha apenas esse gênero. HARTMAN (1959) registra como autor SOUTHERN (1914) ainda que este não tenha acrescentado qualquer informação adicional. WestheIDE (1970, 1974) e FAUCHALD (1977a) adotam o critério de HaRTMAN, o que também fazemos.

\section{Pisionidens Aiyar \& Alikunhi, 1943}

Prostômio bem desenvolvido, com dois pares de olhos coalescentes; duas antenas e dois palpos. Os seis primeiros segmentos são desprovidos de cerdas no adulto; os dois anteriores dotados de cirros tentaculares que correspondem ao cirro ventral do primeiro e ao dorsal do segundo segmento. Os parapódios subsequentes são gradualmente maiores e providos de um acículo a partir do sétimo par. Fases juvenis dotadas de cerdas nos segmentos anteriores. Nos machos adultos, alguns segmentos medianos podem exibir sacos espermáticos bem desenvolvidos e parapódios modificados, com o cirro dorsal hipertrofiado.

Apenas uma espécie foi descrita até o presente.

\section{Pisionidens indica (Aiyar \& Alikunhi, 1940)}

Figs 1-4

Pisionella indica Aiyar \& Alikunhi, 1940:89-107, Figs 1-9, 2 ests.

Pisionidens indica Aiyar \& Alikunhi, 1943:4.- Siewing, 1954:81-83, est. 23.- Friedrich, 1956:57.-

Day, 1967:133, Fig. 4-I, f-j.- Hartmann-Schroeder, 1970:64-69, Fig. 25-32.- Westheide, 1974:4.

? Fauveliella pulchra Tebble, 1953:938-944, est. 23.

Revta bras. Zool. 11 (2): 361 - 390, 1994 
Corpo longo e delgado, alcançando cerca de $25 \mathrm{~mm}$ para 70 segmentos. Prostômio cônico com um par de antenas frontais e um par de palpos subulados; dois pares de olhos mais ou menos coalescentes. Segmento peristomial com dois pares de cirros tentaculares longos (Fig. 1). Faringe musculosa, eversível, armada com quatro maxilas quitinosas e boca orlada de papilas curtas. Parapódios unirremes, minúsculos nos seis segmentos anteriores, com cirros dorsais e ventrais articulados; nos segmentos medianos dotados de um lóbulo setígero alongado, com um acículo porém desprovido de cerdas (Fig. 2). Apenas as fases juvenis possuem cerdas, simples e compostas, exclusivamente nos segmentos anteriores.

Sexos separados; nos machos adultos alguns segmentos medianos são dotados de uma vesícula seminal associada a uma papila genital hipertrofiada, configurando um órgão copulador (Fig. 3). Nas fêmeas, alguns segmentos posteriores aos ovígeros possuem um receptáculo seminal que se abre na base dos parapódios (Fig. 4). Pigídio com um par de longos cirros anais.

Material examinado. Dois exemplares (ZUEC 45PB) coletados na zona entremarés na Praia da Fortaleza, Ubatuba (São Paulo) e 11 exemplares (ZUEC 46PB) da região de Cananéia (São Paulo) em praias areno-lodosas. Todos formas jovens, medindo entre 8 e $19 \mathrm{~mm}$.

Distribuição. Descrita originalmente da região de Madras (Índia), a espécie ocorre também na África do Sul e em El Salvador (América Central). No Brasil foi coletada em Ubatuba, São Sebastião e Cananéia, São Paulo (costa sudeste). WESTHEIDE (1974) que descreveu exemplares de São Sebastião, considera sua distribuição como mundial.

\section{CHRYSOPETALIDAE Ehlers, 1864}

Corpo comprimido, com número de segmentos e comprimento variáveis. Dorso geralmente recoberto por páleas largas e estriadas. Prostômio parcial ou totalmente oculto pelos segmentos anteriores, com ou sem olhos; provido de uma a três antenas, um par de palpos ventrais e um tubérculo occipital ou carúncula (gênero Chrysopetalum e Paleanotus; ausente no gênero Bhawania). Segmento peristomial reduzido, mais ou menos fundido com o prostômio; um a dois pares de cirros tentaculares. Parapódios birremes; notopódios com um cirro dorsal e uma fileira de cerdas geralmente expandidas em forma de pálea (exceto no gênero Dysponetus); neuropódios compactos, com um cirro ventral e cerdas unicamente compostas ou simples e compostas.

A identidade entre as familias Chrysopetalidae, Ehlers e Palmyridae, Kinberg é controvertida. Adotamos aqui o critério de PERKINS (1985), que coincide com a opinião de HARTMAN (1959) e de FAUCHALD (1977).

Quatro gêneros estão incluídos na família Chrysopetalidae: Bhawania Schmarda, 1861; Chrysopetalum Ehlers, 1864; Dysponetus Levinsen, 1879 e Paleanotus Schamarda, 1861.

Os crisopetalídeos são tipicamente epibênticos, encontrados em fundos de areia, cascalho e conchas, ou ainda sobre corais e briozoários arborescentes. 

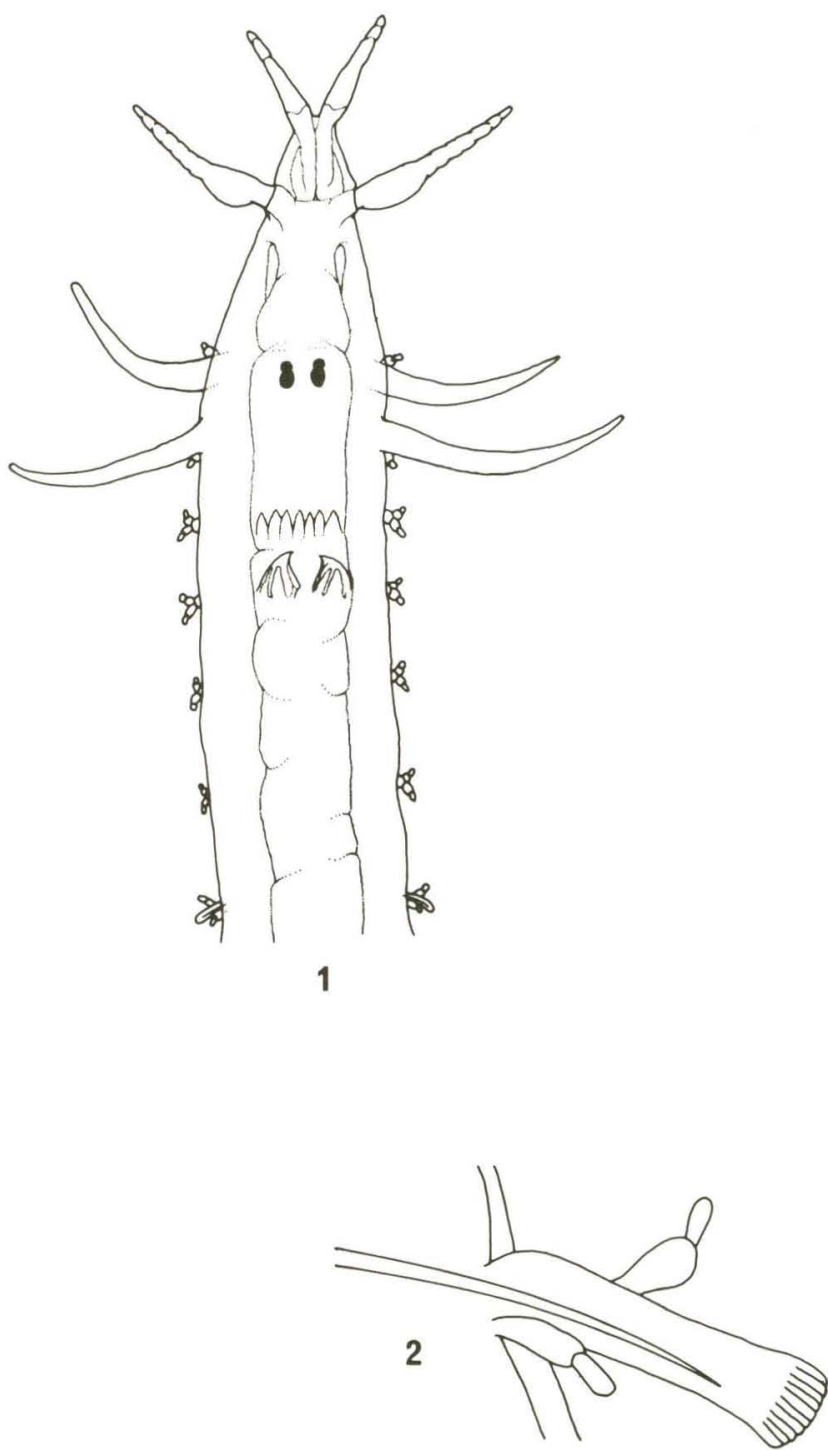

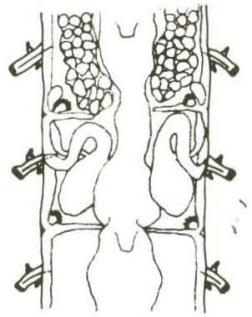

4

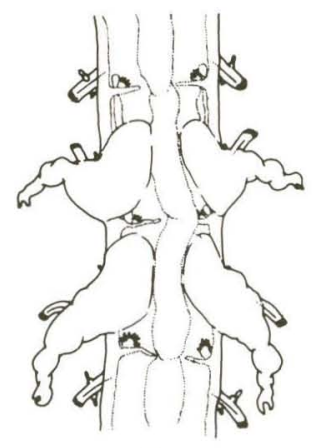

3

Figs 1-4. Pisionidens indica Aiyar \& Alikunhi. (1) Região anterior, vista dorsal; (2) parapódio da região mediana (décimo segmento), animal adulto: (3) região mediana de um macho adulto: (4) região mediana de una fềmea adulta. Figuras adaptadas de Aiyar \& Alikunhi, 1940. 


\section{Chave para gêneros}

1. Cerdas notopodiais pouco ou não comprimidas; não recobrindo o dorso . . . . . . Dysponetus*

- Cerdas notopodiais fortemente comprimidas, em forma de páleas; dispostas em léque ou feixes, recobrindo parcial ou totalmente o dorso (Fig. 5) . . . .2

2. Corpo longo (100 a 300 segmentos). Prostômio retrátil entre os segmentos anteriores; sem carúncula. Páleas superiores largas e simétricas (Fig. 8). Cirros dorsais retráteis . . . . . . . . . . . . Bhawania

- Corpo relativamente curto (30 a 70 segmentos). Prostômio não retrátil; com carúncula geralmente conspícua. Páleas estreitas e recurvadas . . . . . . 3

3. Páleas dispostas em feixes, recobrindo o dorso, exceto ao longo da linha mediana. Cerdas neuropodiais de um único tipo, compostas . . . . . . . . .

Chrysopetalum

- Páleas não recobrindo o dorso. Cerdas neuropodiais simples e compostas . . . . Paleanotus

* Gênero ainda não referido para o Brasil.

\section{Bhawania Schmarda, 1861}

Corpo longo e delgado, com até 300 setígeros; dorso inteiramente recoberto por páleas dispostas em fileiras transversais imbricadas. Prostômio retraído entre os segmentos anteriores, com dois pares de olhos conspícuos e três antenas; sem carúncula. Páleas de dois tipos: as do feixe superior largas, com ápice arredondado; as do feixe lateral, menos numerosas, curtas, estreitas e acuminadas. Cirros dorsais retráteis nos cirróforos. Cerdas neuropodiais compostas, com artículos de comprimento variável.

\section{Bhawania brunnea Morgado \& Amaral, 1981 Figs 5-11}

Bhawania brunnea Morgado \& Amaral, 1981:87-89, Figs 1-6.

Corpo medianamente longo, com cerca de 200 setígeros, alcançando $20 \mathrm{~mm}$ de comprimento, inteiramente recoberto por páleas castanho-douradas. Prostômio minúsculo, normalmente incluso entre os segmentos anteriores e recoberto pelas páleas (Fig. 5), com quatro olhos reniformes, grandes e dispostos em dois pares contíguos, na linha mediana; três antenas subuladas, a mediana com cerca de $1 / 3$ das frontais e inseridas à frente do primeiro par de olhos; um par de palpos em posição ventral, de forma e tamanho semelhantes aos das antenas frontais (Fig. 6); sem carúncula. Parapódios birremes, com lóbulos bem separados. Notopódios quase coalescentes sobre o dorso, providos de páleas de dois tipos: feixe dorsal com cerca de 30 páleas longas e largas (Fig. 7), com cinco costelas principais 


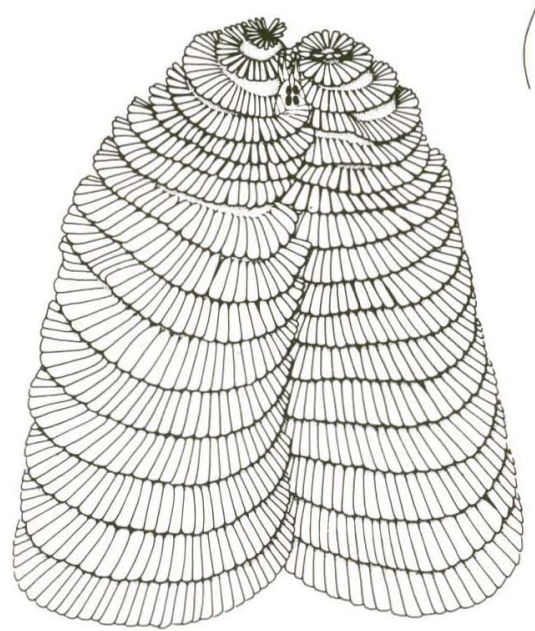

5
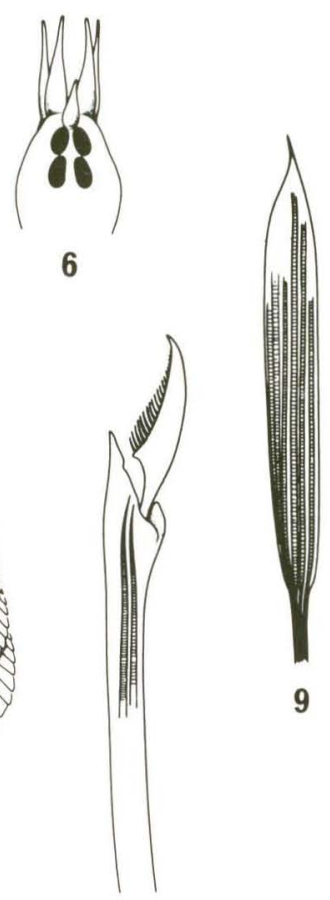

11

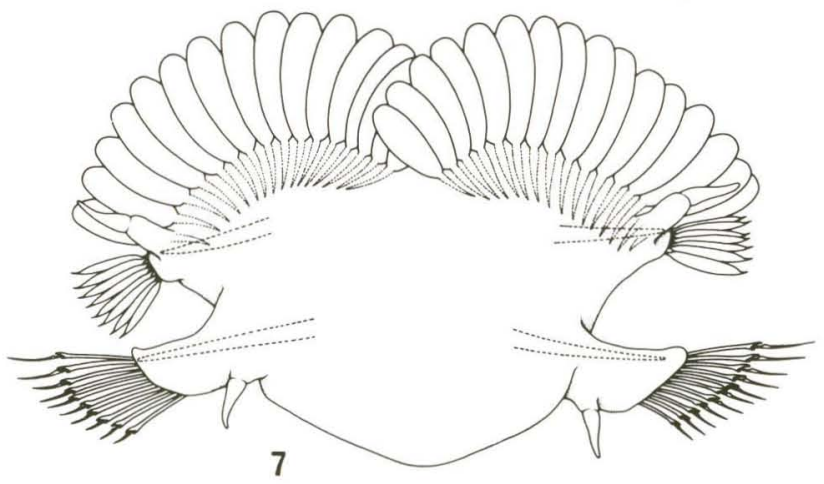

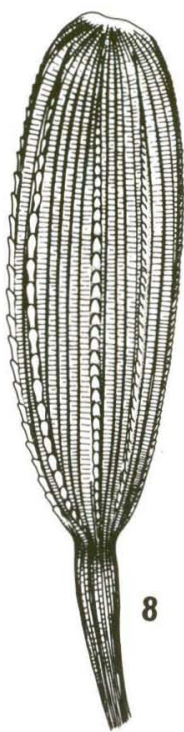
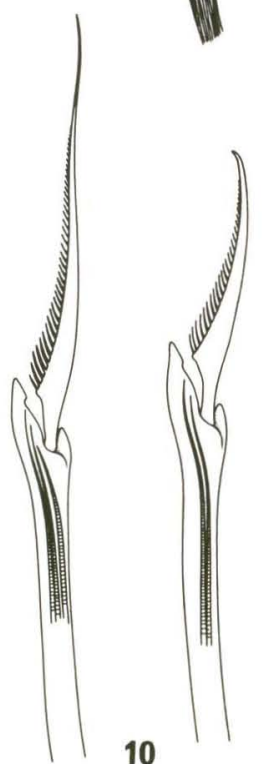

Figs 5-11. Bhawania brunnea Morgado \& Amaral. (5) Região anterior, vista dorsal: (6) detalhe do prostômio: (7) segmento mediano, em corte; (8) pálea dorsal; (9) pálea do feixe lateral; (10) cerda neuropodial superior; (11) cerdas neuropodiais inferiores.

providas de dentes voltados para o bordo distal e cerca de 14 secundárias (Fig. 8); feixe lateral formado por 8-10 páleas mais curtas e estreitas, com ápice acuminado (Fig. 9). Neuropódios truncados obliquamente, com cirro ventral bem desenvolvido, sobre um cirróforo curto; cerdas neuropodiais todas compostas, as 
superiores espinígeras, com artículos gradualmente mais curtos (Fig. 10) e as inferiores falcígeras (Fig. 11).

Discussão. Bhawania brunnea assemelha-se a B. goodei, distinguindo-se desta principalmente pela conformação do prostômio e pela forma das cerdas neuropodiais inferiores com artículos gradualmente mais curtos.

Distribuição. Litoral Norte do Estaco de São Paulo (Ubatuba e São Sebastião), Brasil; em colônias do briozoário Schizoporella unicornis e do poliqueta Phragmatopoma lapidosa.

\section{Bhawania obscura (Grube, 1868)}

Psectra obscura Grube, 1868: 51.

Bhawania obscura; Hartman, 1959: 125.

Corpo longo, vermiforme, com 160-170 segmentos e até 38mm de comprimento. Dorso e parapódios pardo escuro; face ventral cinza-azulado. Olhos e antenas dificilmente visíveis sob as páleas. Notopódios providos unicamente de páleas; neuropódios com cerdas espinígeras e falcígeras, estas em maior número.

Discussão. O gênero Psectra foi criado por Grube, para acolher exemplares de uma espécie referida por Fritz Müller sob o nome de Palmyra obscura, caracterizada pelo grande número de segmentos e pelas fileiras de páleas recobrindo inteiramente o dorso; caracteres que a aproximam, como reconhece o autor, de Bhawania Schmarda.

A descrição de GRUBE, além de suscinta, não é completada com figuras. Não obstante, o comprimento do corpo e o número de setígeros, assim como o recobrimento total do dorso por páleas, justificam sua inclusão no gênero Bhawania. GRUBE menciona a ausência de cirros dorsais; considerando-se que estes são caracteristicamente retráteis, é admissível que não tenham sido notados, o que confirmaria a recondução do material ao gênero Bhawania.

Consideramos a espécie como válida, na expectativa de que coletas sistemáticas na área de ocorrência propiciem material suficiente para dirimir a dúvida.

Distribuição. Conhecida apenas da Ilha de Santa Catarina, na costa sul do Brasil, pelos exemplares coletados por Fritz Müller (GRUBE 1868).

Bhawania goodei Webster, 1884.

Bhawania goodei Webster, 1884:308-309, pl.7, Figs 10-15.- Gardiner, 1975:100, Fig. 5a-e.

Corpo longo e relativamente largo, comprimido, com 220-250 segmentos. Dorso totalmente recoberto por páleas pardo-dourado escuro, não iridescentes. Prostômio profundamente retraído entre os segmentos anteriores; quatro olhos minúsculos, porém muito visíveis; três antenas e dois palpos medianamente desenvolvidos. Segmento peristomial com páleas diminutas, cirros dorsal e ventral e algumas cerdas neuropodiais. Parapódios birremes, típicos do gênero: notopódios em forma de pregas apenas perceptíveis; feixe dorsal com 30-32 páleas largas e um dos bordos espinhoso e 18 nervuras longitudinais; feixe lateral com quatro 
a oito páleas estreitas, mais curtas e ligeiramente curvas, com ápice bruscamente afilado. Cirro dorsal com cirróforo cilíndrico, volumoso. Cerdas neuropodiais compostas; as superiores espinígeras e as inferiores distintamente falcígeras, com artículos de comprimento uniforme.

Material examinado. Quatro exemplares completos (ZUEC 47PB), o maior dos quais com cerca de 250 setígeros e $22 \mathrm{~mm}$ de comprimento; coletados sobre banco natural de ostras.

Distribuição. África Ocidental, Carolina do Norte, USA; Antilhas e Golfo do México; Indo-Pacífico até o Japão, Mar Vermelho. Brasil, São Paulo (litoral norte) e Rio de Janeiro (Parati).

\section{Chrysopetalum Ehlers, 1864}

Corpo relativamente longo, raramente com mais de 65 segmentos. Prostômio visível dorsalmente, com uma carúncula bem desenvolvida, no bordo posterior; dois pares de olhos; antena mediana curta e inserida atrás dos olhos anteriores, as laterais longas e em posição ventral; palpos robustos. Parapódios birremes a partir do terceiro segmento, com notopódios providos de páleas dispostas em grupos recobrindo o dorso; cerdas neuropodiais espinígeras nos segmentos anteriores e falcígeras nos medianos e posteriores; cirros dorsais dos setígeros medianos com cirróforos e cirróstilos longos, com extremidade afilada. Pigídio com um par de uritos semelhantes aos cirros dorsais.

\section{Chrysopetalum occidentale Johnson, 1897}

Chrysopetalum occidentale Johnson, 1897:161-162. est. 5. Figs 15-16, est. 6. Figs 17-19.- Johnson. Hartman, 1961:56; Imajima \& Hartman, 1964:47-48, est. 9. Figs a-g.- Fauchald, 1977b:71, Fig. 18 a-c,- Morgado \& Amaral, 1981:89.- Perkins, 1985: 869-872. Figs 3 e 4.- Gathof, 1984:26-4. Fig. 2a-c.- Uebelacker \& Johnson, 1984: 26-4, Figs 26-1. 2a-c.

Corpo elíptico alongado, alcançando cerca de $15 \mathrm{~mm}$ de comprimento e $1,6 \mathrm{~mm}$ de largura, com até 66 segmentos; ainda que geralmente de proporções e números de segmentos muito menores. Prostômio pequeno, oval e globuloso; quatro olhos, os anteriores muito juntos, ligeiramente maiores e visíveis através do tegumento; antena mediana inserida junto ao bordo anterior, antenas laterais tão longas quanto o prostômio, com inserção ventral; carúncula globular, no bordo posterior; palpos robustos, em posição ventral, mais longos que as antenas. Parapódios com lóbulos notopodiais e neuropodiais subiguais, com o cirro ventral quase tão longo quanto o dorsal. Cerca de 30 páleas petalóides com bordo serrilhado, em cada parapódio, as dorsais mais longas e largas que as laterais. Cerdas neuropodiais dos segmentos anteriores compostas espinígeras heterogonfas, com artículo unidentado e margens serrilhadas.

Distribuição. Da Califórnia ao Panamá; Golfo do México; Ártico Siberiano; Austrália; Norte do Japão; costa sudeste do Brasil.

PERKINS (1985) questiona a identificação dos espécimes provenientes do Ártico, Austrália e Japão. 


\section{Paleanotus Schmarda, 1861}

Corpo relativamente curto, com cerca de 40 segmentos. Prostômio visível entre as páleas; dois pares de olhos, três antenas e dois palpos subulados, em posição ventral; carúncula reduzida ou ausente. Parapódios do segmento peristomial e dos próximos providos unicamente de páleas, cirros dorsal e ventral; demais parapódios birremes. Cerdas neuropodiais compostas, espinígeras ou falcígeras.

O gênero Paleanotus Schmarda se distingue de Bhawania essencialmente pelo tamanho reduzido e pelo número de segmentos, que neste último pode alcançar mais de 200; sendo a carúncula, quando presente, rudimentar.

\section{Paleanotus chrysolepis Schmarda, 1861}

Paleanotus chrysolepis Schmarda, 1861:163, est. 37, Fig. 326-329.-Day, 1967:116-117, Fig. 2.I1-m.Rullier \& Amoureux, 1979:156.- Gathof, 1984:26-6, Fig. 4a-c.

Corpo curto e delgado, com cerca de $15 \mathrm{~mm}$ de comprimento, para 40 setígeros. Prostômio com dois pares de olhos bem visíveis; antenas laterais mais longas que a mediana, dirigidas para a frente; carúncula inconspícua; palpos robustos. Páleas não alcançando a linha mediana; as primeiras do feixe dorsal simétricas, com 15 a 17 nervuras e os bordos espinhosos; as demais, recurvadas, assimétricas e com o ápice junto ao bordo interno. Cerdas neuropodiais compostas, falcígeras, unidentadas e de comprimento variável.

Discussão. A descrição de RULLIER \& AMOUREuX (1979) é sumária e não acompanhada por figuras, sendo complementada aqui com a de DAY (1967). AUGENER (1913) discute longamente as afinidades da espécie, da qual considera sinônimo Heteropale bellis Johnson, 1897.

Distribuição. Califórnia, Golfo do México, África do Sul, Madagascar, Austrália e Mar Vermelho. Brasil: costa sudeste (Espírito Santo) material examinado por RULLIER \& AMOUREUX (1979).

\section{AMPHINOMIDAE Savigny, 1818}

Corpo robusto, com número variável de segmentos (50 a mais de 200), geralmente de secção quadrada ou retangular. Prostômio pequeno, parcialmente retraído entre os segmentos anteriores; com duas regiões bem distintas: um lóbulo anterior dorsalmente arredondado e sulcado na face ventral, com um par de palpos laterais cirriformes, o primeiro par de olhos e duas antenas dorsais; um lóbulo posterior, aproximadamente quadrado, com o segundo par de olhos, a antena mediana e uma carúncula usualmente volumosa e de forma variável, faringe inerme. Parapódios birremes; notopódio com um ou dois cirros dorsais, brânquias ramificadas em tufos e cerdas simples, vítreas e ôcas. A presença de veneno no interior destas cerdas, referida por alguns autores, não foi confirmada no material brasileiro. Neuropódios com um único cirro ventral e cerdas simples.

A família Amphinomidae inclue os gêneros Amphinome Bruguière, 1789; 
Bathychloeia Horst, 1910; Benthoscolex Horst, 1912; Branchamphinome Hartman, 1967; Chloeia Savigny, 1818; Chloenopsis McIntosh, 1885; Chloenea Kinberg, 1867; Eurythoe Kinberg, 1857; Hermodice Kinberg, 1857; Hipponoe Audouin \& Milne-Edwards, 1830; Notopygos Grube, 1855; Parachloeia Horst, 1912; Paramphinome Sars, 1869; Pareurythoe Gustafson, 1930; Pseudeurythoe Fauvel, 1932; Pherecardia Horst, 1886; Pherecardites Horst, 1912; Sangiria Horst, 1911; destes apenas oito são descritos para o Brasil.

Amphinomideos são poliquetos carnívoros e de movimentos lentos, que vivem em águas rasas em fundos lodosos, arenosos ou de corais. São poliquetos que apresentam uma exuberante coloração principalmente em regiões tropicais.

\section{Chave para gêneros}

1. Corpo curto, largo e ovalado. Carúncula bem desenvolvida (Fig. 16) . . . . 2 - Corpo curto, fusiforme. Sem carúncula . . . . . . . . . Hipponoe

- Corpo longo, linear, com segmentos geralmente numerosos. Com carúncula . 3

2. Brânquias penadas. Um único cirro dorsal em cada parapódio (Fig. 15). . . . .

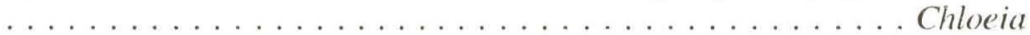

- Brânquias digitadas; dois cirros dorsais em cada parapódio (Fig. 30) . . . . . . . Notopygos

3. Carúncula pouco desenvolvida. Brânquias apenas na região anterior ao corpo .

- Carúncula bem desenvolvida. Brânquias até a extremidade posterior . . . . . 5

4. Com cerda acicular, dirigida para a frente, no primeiro setígero (Fig. 33). . . Paramphinome

- Sem cerda acicular no primeiro setígero. . . . . . . . . Pseudeurythoe

5. Carúncula cordiforme (Fig. 12). Cerdas neuropodiais curtas, recurvadas de

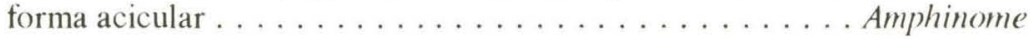

- Carúncula trilobada (dividida por pregas longitudinais - Fig. 17). Cerdas neuropodiais forqueadas . . . . . . . . . . . Eurythoe

- Carúncula volumosa e multilobada (Fig. 24). Cerdas neuropodiais em forma de

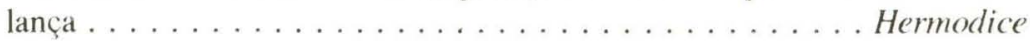

\section{Amphinome Bruguières, 1789}

Corpo geralmente muito longo, de secção angulosa, com até 300 setígeros. Prostômio típico da família, com uma carúncula pequena, cordiforme. Notopódios com um único cirro dorsal e brânquias arborescentes, uma por parapódio, até os 
últimos segmentos. Cerdas notopodiais numerosas, capilares e em arpão; cerdas neuropodiais em pequeno número, robustas, aciculares ou uncinadas.

\section{Amphinome rostrata (Pallas, 1776) \\ Figs 12-14}

Aphrodita rostrata; Quatrefages, 1865: 394-395.

Amphinome rostrat Hartman, 1951:22. est. 4 Fig. 1.- Pettibone, 1963:59, Fig. 13d-e.- Day, 1967:123. Fig. 3.1.j-k.- Gardiner, 1975:101. Fig. 5j-k.

Corpo longo, alcançando $250 \mathrm{~mm}$ de comprimento e cerca de 200 a 250 setígeros. Prostômio convexo dorsalmente e profundamente sulcado na face ventral; com um par de palpos laterais, três antenas dorsais e dois pares de olhos; carúncula relativamente pequena, lisa e cordiforme, alcançando o segundo setígero (Fig. 12). Brânquias em tufo, ramificadas (Fig. 13), a primeira no segundo ou terceiro setígero (Fig. 12); presentes até os últimos segmentos. Cirro dorsal único, cerdas notopodiais capilares e em arpão, com o bordo serrilhado. Neuropódios muito curtos, amplamente separados do notopódio, com cerdas aciculares e duas a três cerdas curtas, grossas e recurvadas (Fig. 14).

Material examinado. Três exemplares, o maior dos quais com 208 setígeros, coletados entre blocos de algas calcárias, no litoral de Pernambuco (ZUEC-50PB).

Distribuição. Oceanos tropicais. Segundo DAY (1967), comum em corpos flutuantes. No Brasil foi coletada no litoral do Estado de Pernambuco (Cabo de Santo Agostinho); sendo sua presença também referida para o litoral do Estado do Rio de Janeiro e de São Paulo.

\section{Chloeia Savigny, 1818}

Corpo curto, ovalado, segmentos pouco numerosos. Prostômio arredondado com quatro olhos. Carúncula longa com muitas pregas transversais. Uma antena mediana tão longa quanto a carúncula, dois laterais e dois palpos filiformes. Parapódios birremes. Cerdas notopodiais serrilhadas, bifurcadas e lisas. Cerdas neuropodiais bífidas, lisas. Cirros dorsais e ventrais presentes. Brânquias penadas.

\section{Chloeia viridis Schmarda, 1861}

Figs 15-16

Chloeia viridis Schmarda. 1861:144. est. 25. Fig. 295-305.- Monro. 1933:9-10. Fig. 4.- Fauvel \& Rullier, 1957:54-57, Fig. 2.- Rullier. 1964:144-145 - Nonato \& Luna, 1970:65, Figs 1-2.

Chloeia euglochis Ehlers, 1887:18-24, est. 1, Figs 1-2. est. 2. Figs 1-8, est. 3, Figs 1-4.

Chloenea candida Kinberg, 1910:33, est. 11, Fig. 2.

Corpo fusiforme, comprimido, com cerca de 26 setígeros (Fig. 15). Prostômio pequeno e arredondado, com dois palpos filliformes; uma antena mediana, longa e duas laterais muito curtas; dois pares de olhos. Carúncula em crista finamente pregueada, longa e subulada; reta ou ligeiramente sinuosa (Fig. 16). 

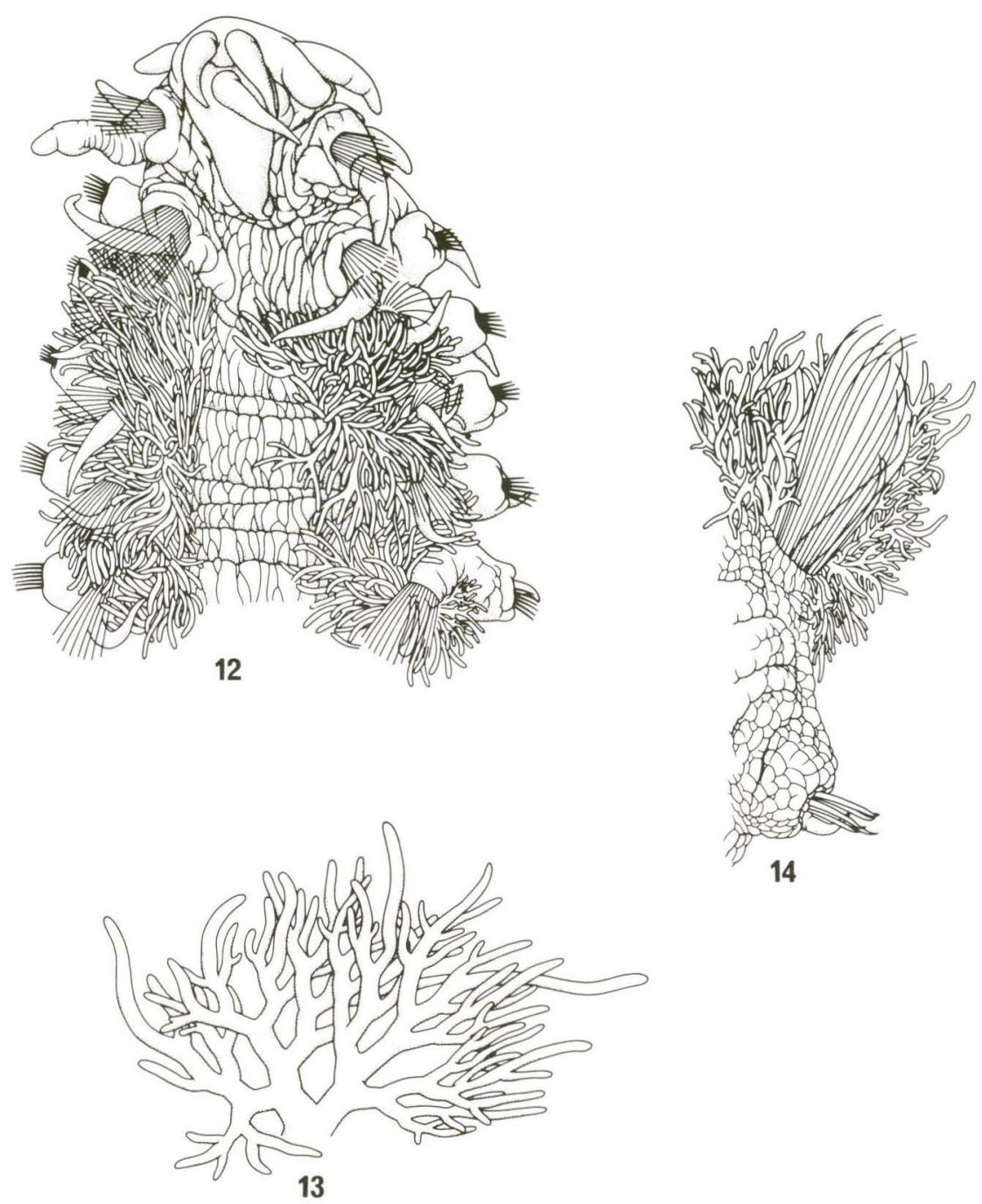

Figs 12-14. Amphineme restrata (Pallas). (12) Regiào anterior. vista dorsal: (13) detalhe de un tronco branquial: (14) parapódio do décimo setígero.

Segmentos largos e bem separados. Brânquias dorsais, penadas, a partir do quarto setígero. Cirros dorsais e ventrais muito longos, subulados; nos dois ou três primeiros setígeros os cirros dorsais são duplos. Cerdas muito numerosas, sendo as notopodiais bifurcadas em extensão variável. Cerdas vítreas, incolores ou ligeiramente amareladas

Distribuição. Atlântico tropical; Mediterrâneo; Índico e Pacífico (FAUVEL \& RULLier 1957). Na costa americana; da Flórida até o Nordeste do Brasil (Alagoas). 

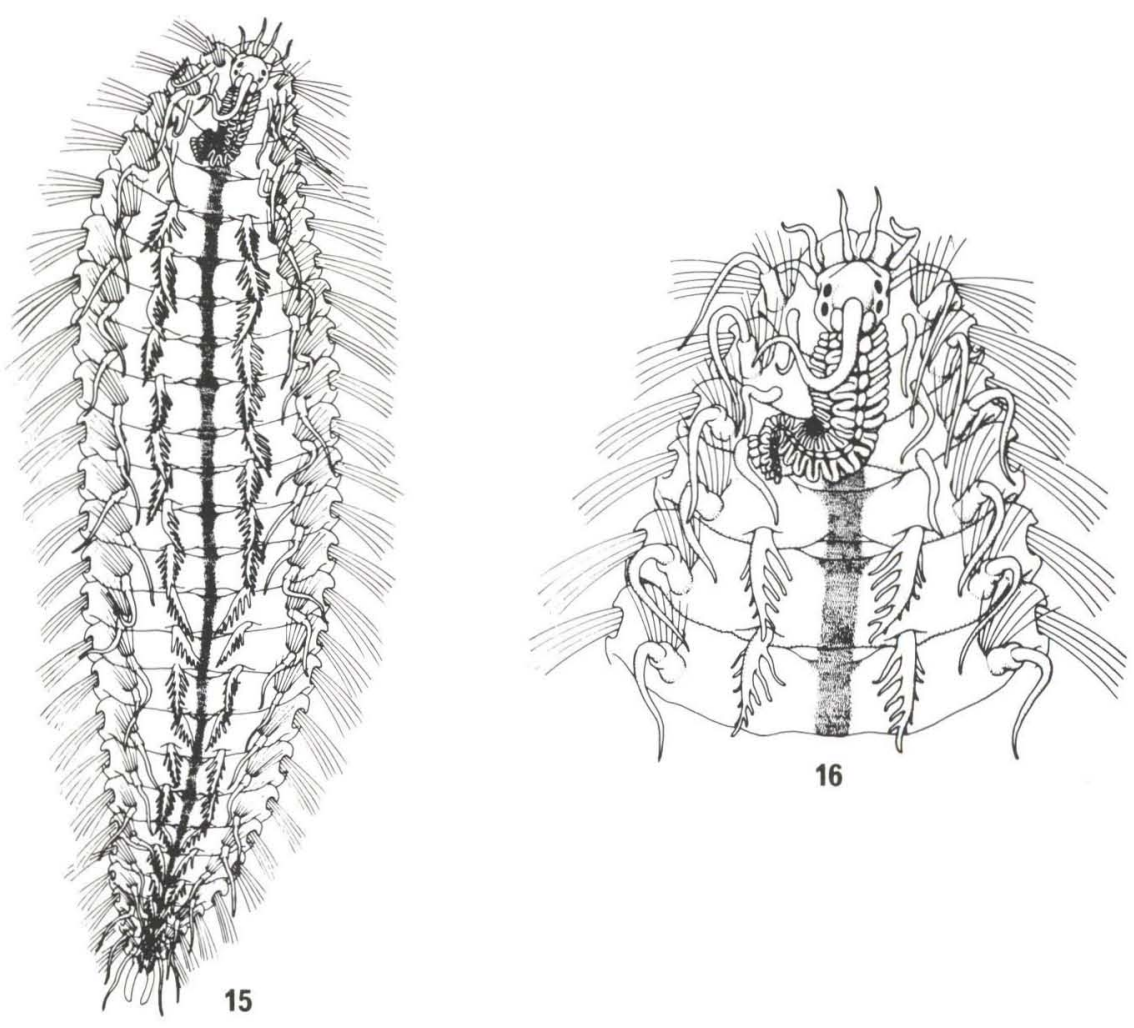

Figs 15-16. Chloeic viridis Savigny. (15) Animal total, vista dorsal; (16) detalhe da região anterior.

\section{Eurythoe Kinberg, 1857}

Corpo alongado, com secção retangular, alcançando cerca de $120 \mathrm{~mm}$ de comprimento. Prostômio bem desenvolvido, com dois pares de olhos, três antenas e um par de palpos articulados. Carúncula longa e estreita, com pequenas pregas laterais, parcialmente ocultas sob uma quilha volumosa. Parapódios com lóbulos bem separados; cerdas notopodiais simples e em arpão; cerdas neuropodiais todas forqueadas. Brânquias em tufos, a partir do primeiro ao terceiro setígero, pouco ramificadas.

\section{Eurythoe complanata (Pallas, 1776)}

Figs 17-23

Eurythoe complanata (Pallas). Fauvel, 1953:83. Fig. 38b-m.- Hartman, 1968:195, Figs 1-4.- Nonato \& Luna, 1970:65-66.

Eurythoe brasiliensis Hansen, 1882:4, est. 1. Figs 5-9.

Corpo relativamente longo, de secção quadrada ou retangular. Prostômio grande, arredondado, com quatro olhos sub-iguais, dispostos em quadrado; antenas 

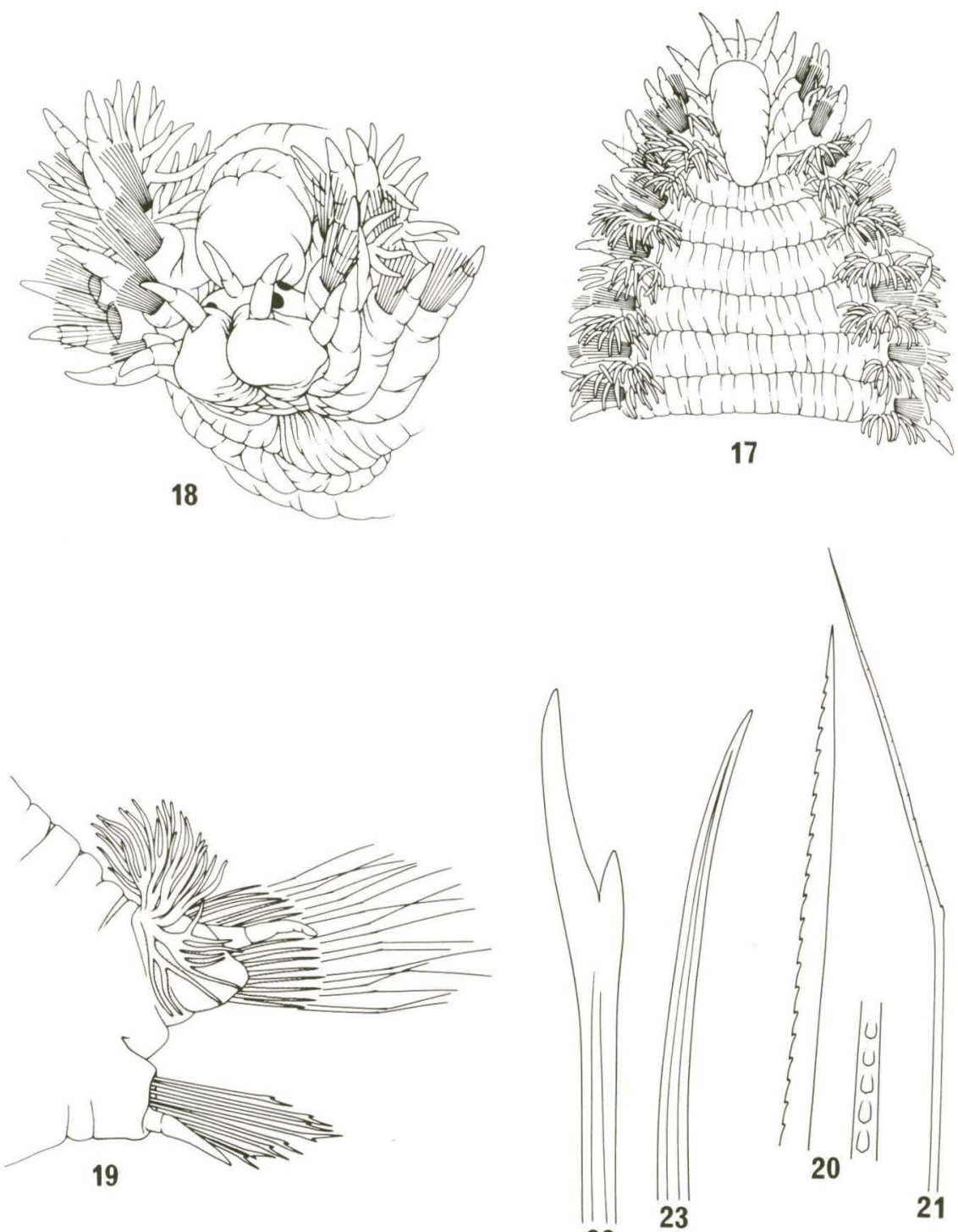

22

Figs 17-23. Eurythoe complanata (Pallas). (17) Região anterior, vista dorsal; (18) Regiāo anterior. vista de frente; (19) parapódio mediano; (20) cerda notopodial curta: (21) cerda notopodial longa: (22) cerda neuropodial forqueada; (23) cerda notopodial dos segmentos anteriores. 
piriformes-subuladas; carúncula linear, bem desenvolvida, alcançando o quarto ou quinto setígero (Figs 17-18). Brânquias a partir do segundo setígero; o primeiro par em forma de filamento simples e curto; as do terceiro setígero palmadas, com quatro filamentos e as subsequentes com 12 a 20, em tufo compacto (Figs 17 e 19). Ramos parapodiais bem separados, com cirros dorsais e ventrais subulados, medianamente longos. Cerdas notopodiais simples e em arpão (Figs 20-21); cerdas neuropodiais aciculares, retas e forqueadas, com o ramo maior liso ou denticulado (Figs 22-23). Cor no álcool: amarelo-alaranjado; cerdas branco-alabrasto.

Discussão. Ainda que $E$. complanata seja espécie ocasionalmente robusta, espécimes de pequeno porte não são raros; Monro (1930) examinou 28 exemplares das Ilhas Ascensão e do Golfo da Guiné, o maior dos quais com apenas $30 \mathrm{~mm}$ de comprimento.

HANSEN (1882), descrevendo Eurythoe brasiliensis do Rio de Janeiro espécie que HARTMAN (1959) considera sinônimo de $E$. complanata - atribui à sua espécie uma carúncula longa, alcançando o quarto anel; brânquias "arbusculiformes" a partir do segundo setígero e cerdas neuropodiais forqueadas, lisas. Tais caracteres confirmam a identidade das duas espécies, justificando a decisão de HARTMAN.

Distribuição. Amplamente distribuida nos mares tropicais e temperados. No Brasil, sua presença foi assinalada no Nordeste (Alagoas); sendo muito frequente no litoral Norte de São Paulo (São Sebastião).

\section{Hermodice Kinberg, 1857}

Corpo alongado. Prostômio arredondado, com dois pares de olhos; três antenas e dois palpos subulados. Carúncula volumosa multilobada, se extendendo até o quarto setígero. Parapódios birremes; cerdas notopodiais capilares subuladas, lisas ou denticuladas; cerdas neuropodiais sub-bífidas denticuladas e em forma de lança. Cirros dorsais e ventrais presentes. Brânquias em tufos ramificadas presentes a partir do primeiro setígero.

\section{Hermodice carunculata (Pallas, 1776)}

Figs 24-29

Hermodice cartunculata; Fauvel, 1923:130-132, Fig. 47a-i.

Corpo longo e robusto com 60 a 150 setígeros de comprimento. Prostômio pequeno com quatro olhos; uma antena mediana cônica, duas antenas laterais muito mais curtas que a mediana e dois palpos semelhantes as antenas laterais. Carúncula ovalada sem uma distinta prega mediana, com dobras transversais formando lobos foliáceos (Fig. 24). Parapódios com os ramos bem separados. Notopódios com um cirro filiforme, um feixe de cerdas longas finas, moles e lisas, outras curtas e grossas, igualmente lisas e algumas denteadas, em arpão (Figs 25-27). Cerdas neuropodiais grossas e curtas, lisas ou apresentando somente denticulações na extremidade (Figs 28-29), com um pequeno esporão. Cirro ventral curto, brânquias grandes e arborescentes. 


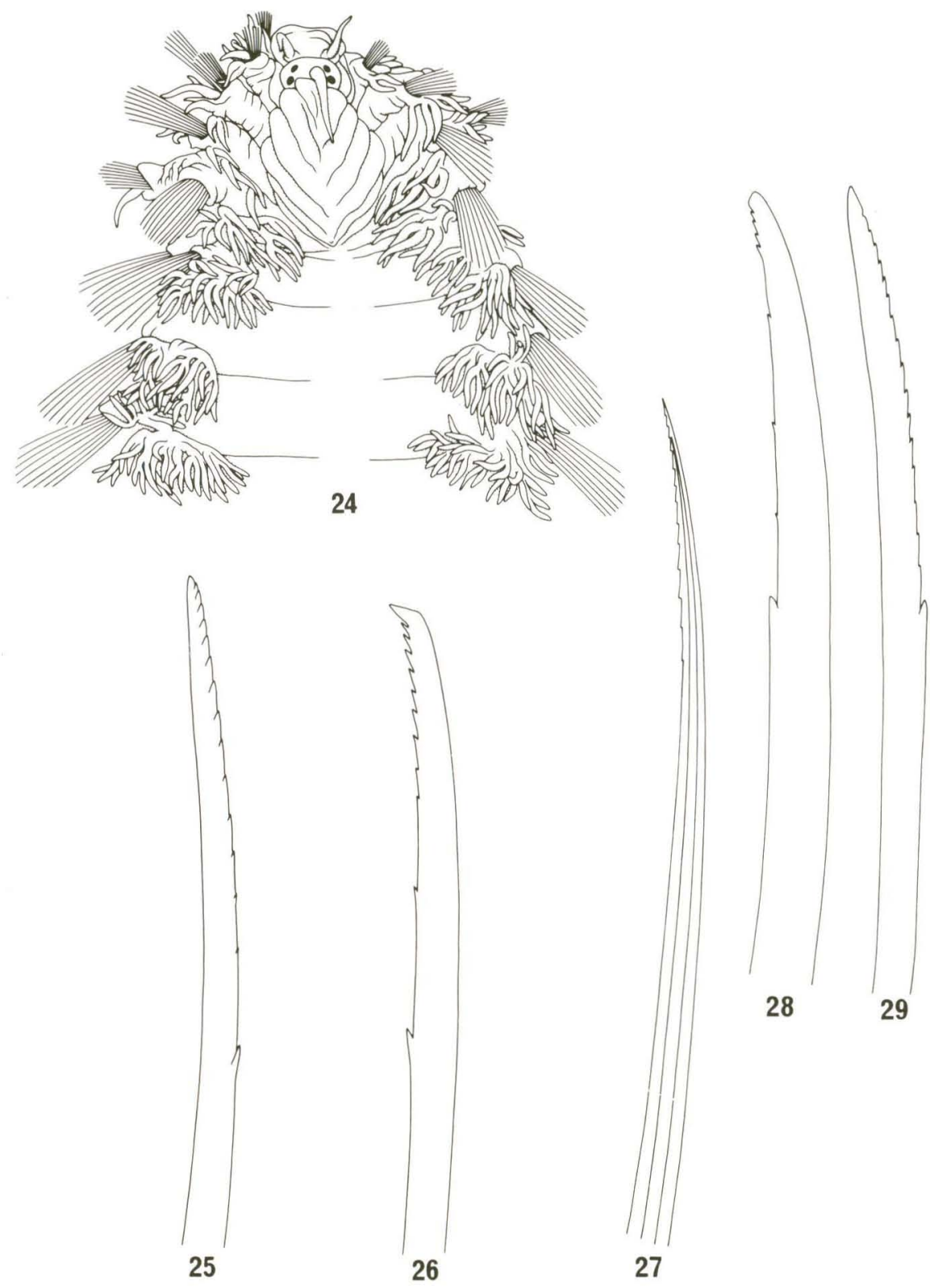

Figs 24-29. Hermodice carunculata (Pallas). (24) Região anterior. vista dorsal: (25-26) cerdas notopodiais; (27) cerda notopodial dos segmentos anteriores; (28) cerda neuropodial, do feixe superior: (29) cerda neuropodial do feixe inferior. 
Material examinado. Dois exemplares coletados no litoral de Pernambuco (ZUEC -51PB).

Distribuição. Mar do Norte, Atlântico, Mediterrâneo. No Brasil foi coletado no litoral do Estado de Pernambuco.

\section{Hypponoe Audouin \& Milne-Edwards, 1830}

Corpo curto, fusiforme, com segmentos pouco numerosos. Carúncula ausente. Prostômio com olhos, uma antena mediana, dois laterais e dois palpos subulados. Parapódios birremes. Notopódio com um cirro filiforme e um feixe de cerdas capilares. Neuropodio reduzido, com cerdas curtas e robustas, cirro ventral ausente. Brânquias em tufos ramificadas em todos os segmentos a partir do terceiro setígero.

Discussão. Tanto na descrição original quanto em 1833 os autores registraram Hipponoe. HARTMAN (1959) refere Hipponoa, com a variante Hipponoe, possivelmente modificado por uma referência (a nosso ver, simples erro tipográfico) na segunda edição de "Reino Animal" de Cuvier editado em 1832.

\section{Hypponoe gaudichaudi Audouin \& Milne-Edwards, 1830}

Hypponoe gaudichaudi Audouin \& Milne-Edwards, 1830: 156-159, est. 3.- 1833: 202-203, est. 9.Pettibone, 1963:57, Fig. 13a-b.- Gardiner, 1975:103.- Salazar-Vallejo, 1992: 216-217, Fig. Id-e.

Corpo curto, vermiforme e comprimido, com 35 setígeros e medindo $28 \mathrm{~mm}$ de comprimento no exemplar examinado. Prostômio sub-oval com quatro olhos; duas antenas laterais curtas e uma antena mediana muito mais longa; dois palpos em posição ventro-lateral; sem carúncula. Parapódios com o notopódio em posição latero-dorsal, com cirro dorsal digitado e cerdas dispostas em léque, todas capilares com extremidade bífida; neuropódios curtos, com uma prega circular de onde emergem cerdas curtas e robustas, recurvadas. Brânquias arborescentes, a partir do terceiro setígero, até a extremidade posterior.

Material examinado. Um exemplar, coletado no Canal de São Sebastião, em bloco de asfalto flutuante (ZUEC - 52PB).

Distribuição. Segundo Gardiner (1975): Cosmopolita, em objetos flutuantes. No Brasil, São Sebastião, São Paulo.

\section{Hypponoe gaudichaudi agulhana Day, 1967}

Hypponoa gaudichaudi agulhana Day, 1967:122, Fig. 3.I a-e.- Orenzanz \& Gianuca, 1974:7.- Lana, 1984:48-49, Fig. 45.

Forma curta e achatada. Prostômio sub-oval; com quatro olhos, acompanhados de duas a três manchas ocelares anteriores; uma antena mediana longa e duas antenas laterais curtas; dois palpos antero-ventrais. Notopódios e neuropódios muito afastados um do outro; os últimos em posição tipicamente ventral. Cirros dorsais em posição inferior à das cerdas superiores. Cerdas notopodiais capilares, delicadas e lisas, com extremidade inteira. Neuropódios com ganchos robustos 
bidentados, retráteis, presentes a partir do segundo setígero. Cirros ventrais em forma de almofada. Brânquias arborescentes, a partir do terceiro setígero.

Discussão. Hypponoa gaudichaudi agulhana, descrita da África do Sul, difere da espécie-tronco por não possuir cerdas capilares com extremidade bífida e pela forma dos ganchos ventrais com o dente secundário fortemente recurvado.

Distribuição. África do Sul; no Brasil, foi referida para o Rio Grande do Sul e Paraná. Ocorre sobre corpos flutuantes, associada com Lepas anatifera Linnaeus.

\section{Notopygos Grube, 1855}

Corpo ovalado, com segmentos pouco numerosos. Prostômio arredondado com uma antena mediana curta, dois laterais e dois palpos filiformes. Carúncula bem desenvolvida, fusiforme. Parapódios hirremes; notopódios com dois cirros dorsais e cerdas hifurcadas lisas ou denteadas; neuropodios com cerdas semelhantes e um cirro ventral. Brânquias digitadas com um único tufo de filamentos começando no quinto setígero e presente nos segmentos posteriores.

\section{Notopygos crinita Grube, 1855}

Figs 30-32

Notopygos crinita: Ehlers. 1887:24-26, est. 1. Fig. 3. est. 3, Figs 5-7.- Treadwell. 1939:175-176.Nonato \& Luna, 1970:66, Figs 3-4.

Notopygos crinitus: Kinberg, 1910:33, est. 11, Fig. 3.

Corpo curto e fusiforme, comprimido; segmentos largos, pouco numerosos (Fig. 30). Prostômio com uma antena mediana, relativamente longa, duas antenas distais e dois palpos subulados, curtos; quatro olhos sub-iguais, dispostos em trapézio. Carúncula robusta, constituída por uma placa basal multilobada e uma crista longitudinal ligeiramente sinuosa e pregueada; sua extremidade posterior alcançando o quinto setígero (Fig. 31).

Brânquias digitadas a partir do sexto setígero, agrupadas em feixes de cinco a oito em cada parapódio. Notopódios com dois cirros, o interno inserido sobre uma base cilíndrica longa (Figs 30-31); neuropódios anteriores com cirro ventral longo, subulado. Cerdas, de um único tipo, bifurcadas, com ramos desiguais. A diferença no comprimento dos ramos é ligeiramente maior nas cerdas neuropodiais. Cirros pigidiais achatados (Fig. 32).

Distribuição. Notopygos crinita era conhecida apenas da Ilha de Sta. Helena e do Mar das Antilhas. A ocorrência atual estende a sua distribuição ao Nordeste Brasileiro (Alagoas).

\section{Paramphinome Sars, 1864}

Forma pequena e longa, de secção quadrangular. Prostômio largo estreitando-se posteriormente em uma pequena carúncula. Uma antena mediana, um par de antenas laterais e um par de palpos. Olhos presentes ou ausentes. Parapódio 

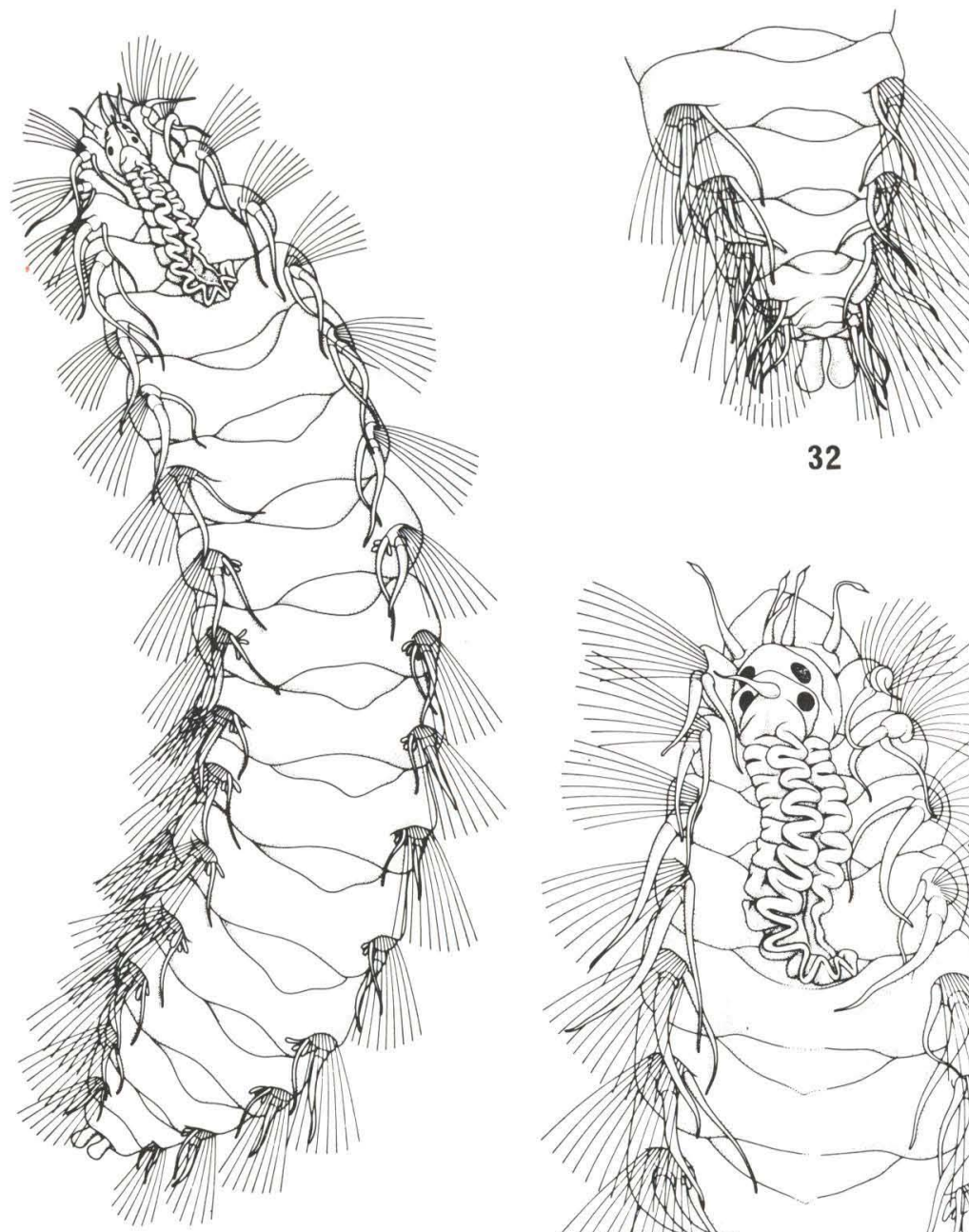

32

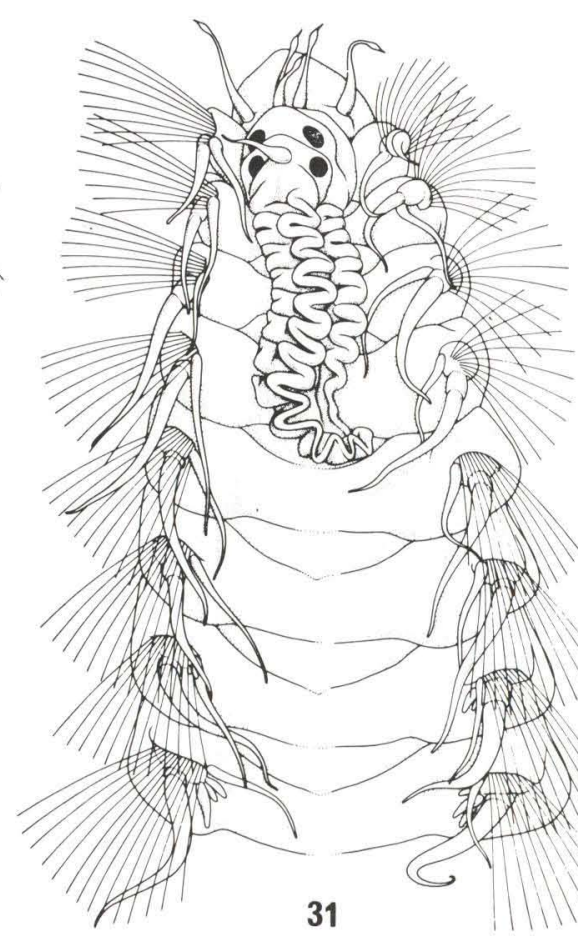

Figs 30-32. Notopygos crinita Grube. (30) Animal total, vista dorsal (brânquias parcialmente retraídas); (31) detalhe da região anterior: (32) detalhe da região posterior.

com apenas um cirro dorsal e um ventral. Primeiro setígero com um a dois ganchos dirigidos para frente. Brânquias em tufos, limitadas aos setígeros anteriores. 


\section{Paramphinome besnardi Temperini, 1981}

Figs 33-37

Paramphinome hesnardi Temperini. 1981:14. Figs 31-35.- Lana. 1984:50. Fig. 47.

Corpo curto, mais largo na região anterior e afilado após a região branquial. Prostômio curto, arredondado, com três antenas e um par de palpos; olhos ausentes e carúncula inconspícua (Fig. 33); tromba evaginável, membranosa e inerme. Brânquias com ramificação dicotômica, limitadas à região anterior, entre quarto e nono setígeros, rebatidas sobre o dorso (Fig. 34). Parapódios birremes, com lóbulos bem separados (Fig. 34); notopódio do primeiro setígero com cirro dorsal muito mais longo que o ventral, com dois ganchos de aspecto vítreo, curtos e robustos (Figs 33-35), as demais cerdas notopodiais capilares, lisas. O segundo setígero é desprovido de cirro ventral. Neuropódios com duas a três cerdas aciculares com o ápice dilatado (Fig. 36) e um feixe de cerdas capilares bífidas e serrilhadas (Fig. 37).

Distribuição. Brasil, costa Sul: Rio de Janeiro e Paraná.

\section{Pseudeurythoe Fauvel, 1932}

Corpo Iongo, vermiforme e de secção retangular, estreitado na região posterior; alcançando cerca de $80 \mathrm{~mm}$ de comprimento e $6-8 \mathrm{~mm}$ de largura. Prostômio arredondado, frequentemente retraído entre os primeiros segmentos; com quatro olhos; antenas e palpos cirriformes, articulados; carúncula inconspícua. Brânquias em tufos ramificados; limitadas à região anterior.

Discussão. O gênero Pseudeurythoe Fauvel não deve ser considerado como sinônimo de Linopherus Quatrefages; sendo insustentável a posição assumida por Fauchald (1977a). A "descrição" de Quatrefages (1965:192) é extremamente suscinta e superficial; não autorizando uma comparação decisiva. A presença de uma carúncula é duvidosa, uma vez que QUATREFAGES tomou como tipo do gênero Amphinome incarunculata Peters, 1854; baseando-se em redescrição de GRUBE (1860:77), o que não é lícito quando se constata que a descrição de GRUBE não confere com a de PETERs (1854). Este refere textualmente: "Diese Art ... zeigt keine Spur einer Carunkel" enquanto GRUBE menciona: "Caruncula ovalis, margine integro ...".

\section{Pseudeurythoe ambigua Fauvel, 1932}

Figs 39-44

Pseudeurythoe ambigua: Fauvel. 1932:46-47.- Gardiner, 1975:103, Fig. 5n-p.- Nonato, 1981:75

Eurithoe ambigua: Monro, 1933:6, Fig. 2.

Linophenus ambigua; Fauchald. 1977b:12.- Lana. 1984:51-52.

Prostômio com três antenas frontais e dois palpos ventro-laterais; carúncula inconspícua (Figs 38-39). Cirros dorsais e ventrais dos primeiros setígeros longos (Fig. 40), nos demais os cirros dorsais são longos e achatados, nitidamente articulados e os ventrais curtos (Fig. 41). Cerdas notopodiais: capilares longas; 

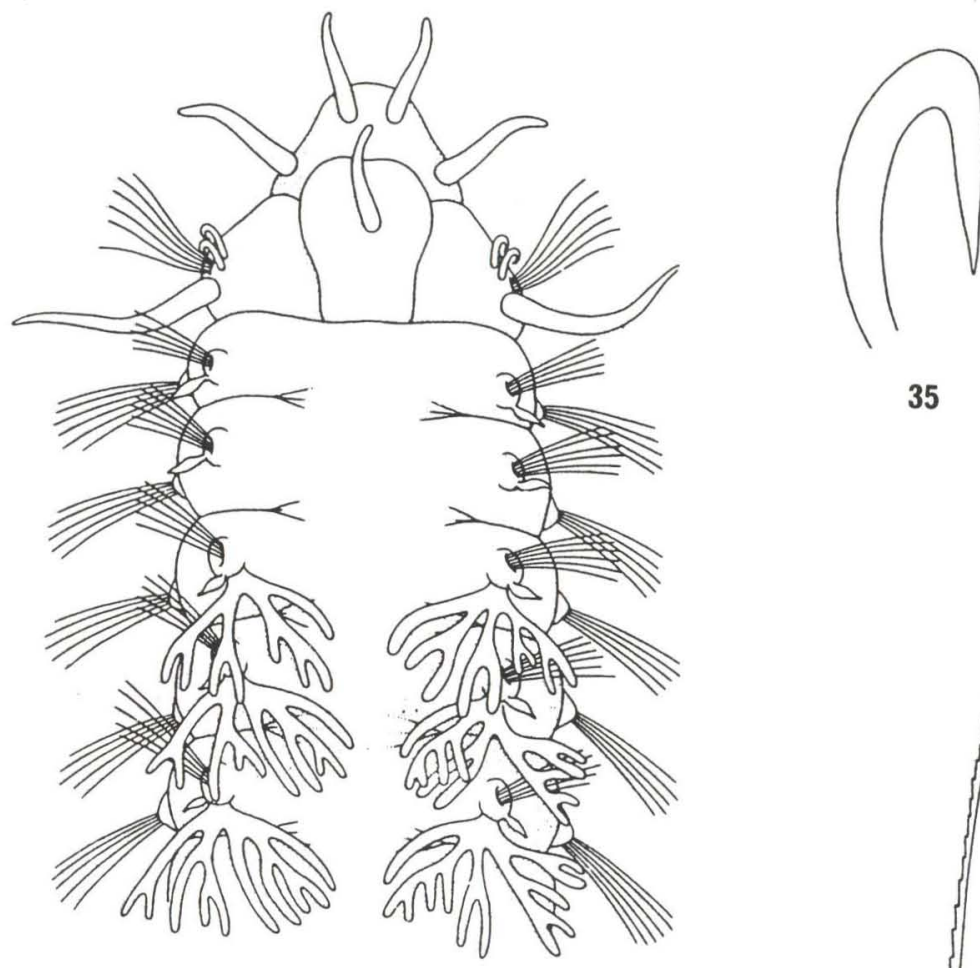

33

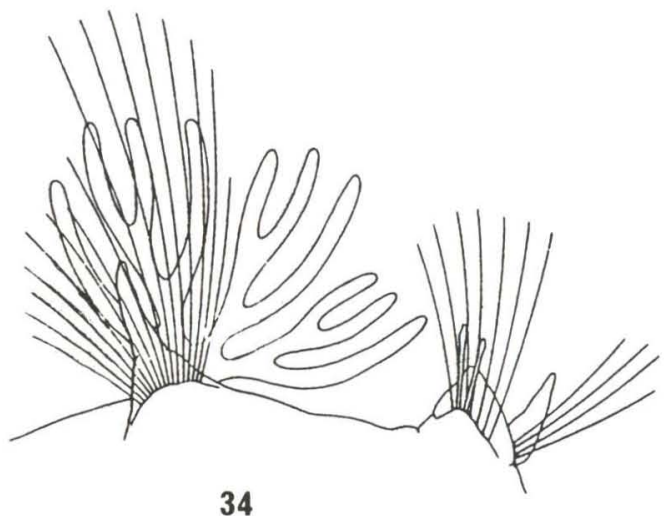

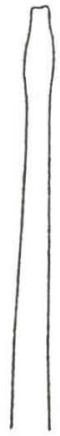

36
35

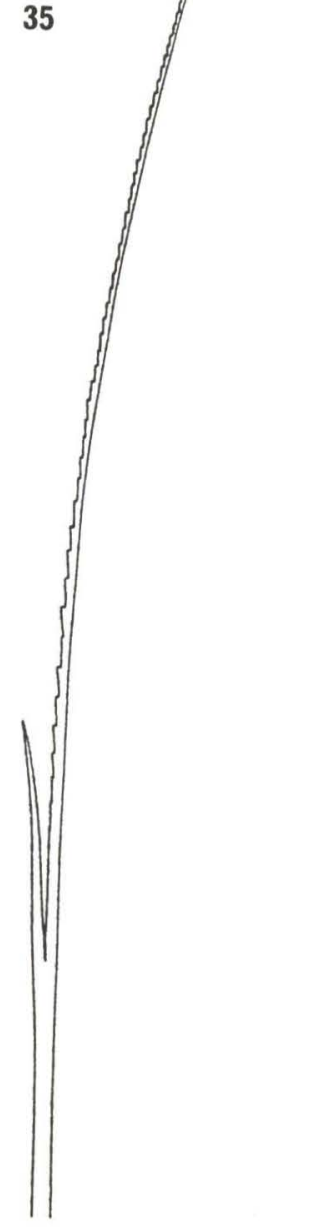

37

Figs 33-37. Paramphinome besnardi Temperini. (33) Região anterior, vista dorsal: (34) parapódio anterior com brânquias: (35) gancho notopodial do primeiro setígero; (36) cerda acicular neuropodial: (37) cerda capilar neuropodial. 

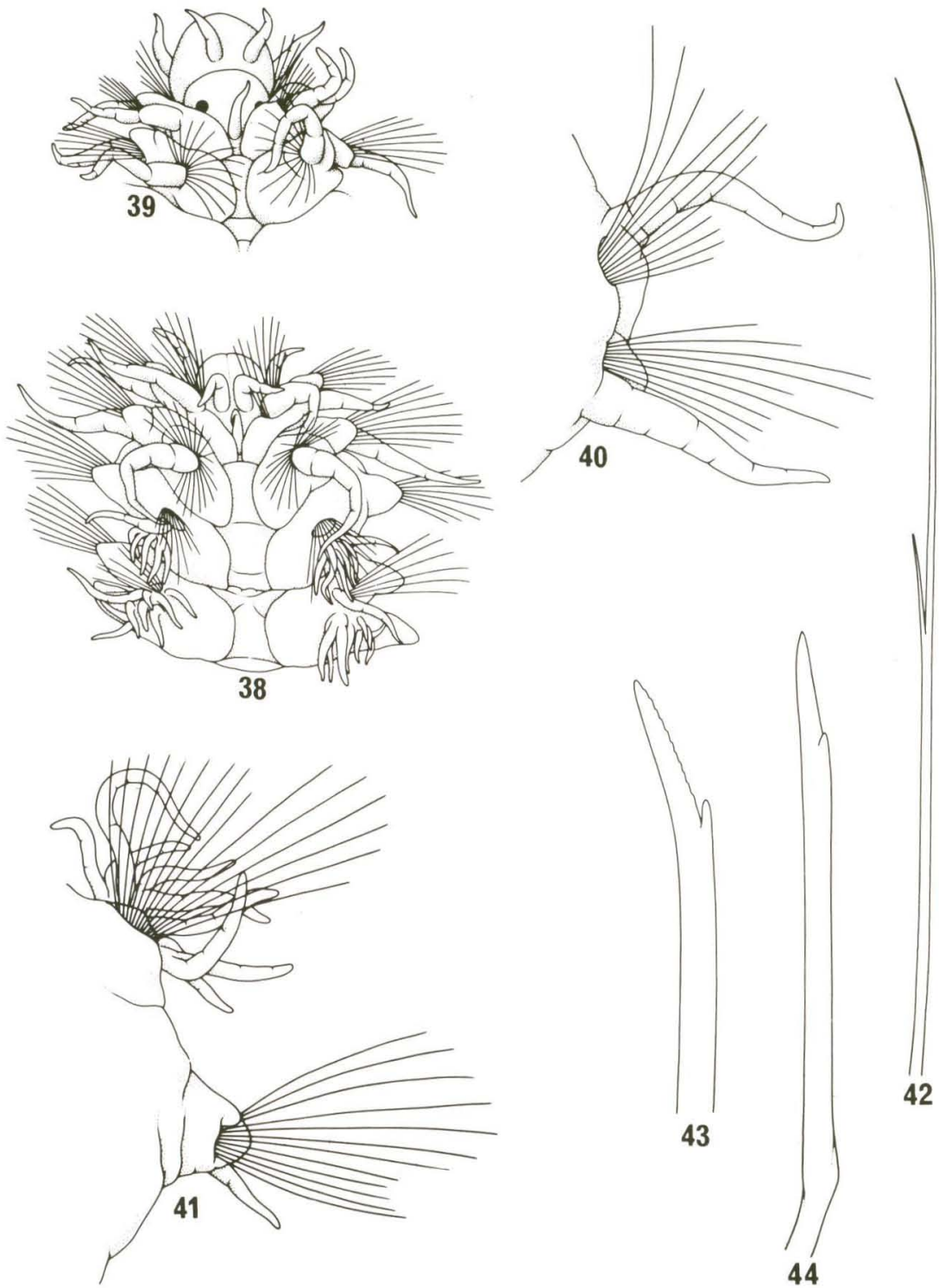

Figs 38-44. Psetuleurythe ambigua Fauvel. (38) Regiào anterior. vista dorsil: (34) detalhe da regiàu anterior e do prostômio: (40) parapódio do segundo setígero: (41) parapódio do décimo setígero; (42) cerda notopodial: (43) eerda neuropodial do feixe superior: (44) cerda neuropodial do feixe inferior.

forqueadas com ramos desiguais e com o ramo maior serrilhado (Fig. 42). Cerdas neuropodiais: capilares longas e forqueadas com ramos desiguais (Figs 43-44). Brânquias em tufos irregulares, presentes do terceiro até o $23^{\circ}$ setígero (Fig. 41). Cor, no vivo, rosa-alaranjado; tufos de cerdas brancos. 
Distribuição. Carolina do Norte; costa Pacífica do Panamá; Índia. No Brasil, ocorre na costa dos Estados de São Paulo (Ubatuba e São Sebastião) e Paraná (Paranaguá).

\section{EUPHROSINIDAE Willians, 1851}

Corpo curto, elíptico e comprimido; com numerosos segmentos e aspecto hirsuto. Prostômio minúsculo, com três antenas e dois palpos ovóides; carúncula bem desenvolvida, simples ou lobada; dois pares de olhos, o anterior em posição ventral. Parapódios birremes, com ramos em forma de pregas alongadas e pouco salientes; um ou dois cirros dorsais e o cirro ventral inserido na face posterior do neuropódio. Cerdas notopodiais dispostas em fileiras transversais, de forma peculiar e aspecto vítreo; cerdas neuropodiais mais delgadas, bifurcadas. Brânquias arborescentes ou digitadas, dispostas entre as cerdas dorsais. Com ou sem ventosas na face ventral da região posterior. Um par de cirros anais globulosos.

Essa família, que contém apenas dois gêneros Euphrosine Savigny, 1818 e Palmyreuphrosyne Fauvel, 1913, foi incluída na Ordem Amphinomorpha por UsHAKOV (1955). Adotamos a grafia para a familia Euphrosinidae segundo KudENOV (1987). Apenas o gênero Euphrosine foi referido para a costa do Brasil.

Os Euphrosinidae são poliquetos carnívoros tipicamente epibênticos; ocorrendo em costões, associados a corais, esponjas ou fundos de areia e cascalho.

\section{Chave para Gêneros}

1. Cerdas notopodiais bifurcadas, de forma variada, com hastes cilíndricas . . . Euphrosine

- Cerdas notopodiais comprimidas, simulando páleas . . . . . Palmyreuphrosyne* * Gênero ainda não referido para o Brasil.

\section{Euphrosine Savigny, 1818}

Corpo curto e largo, fortemente convexo no dorso. Prostômio alongado e recurvado para baixo; dois olhos dorsais e dois ventrais, palpos pequenos; carúncula simples ou tripartida. Cerdas notopodiais numerosas de dois tipos e dispostas em fileiras interpenetradas; cerdas neuropodiais delicadas, lisas ou dentadas, bifurcadas. Brânquias numerosas em todos os segmentos. Sem ventosas.

Discussão. A presença de cerdas notopodiais com a região distal comprimida e alargada, fendida (que lembra uma boca com dentes), denominadas por JOHNSON (1897) ringente, é característica para a maioria das espécies atualmente conhecidas (aproximadamente 50). KUDENOV (1987) considera o termo inadequado para descrever estas cerdas; não obstante, o aspecto das mesmas é extremamente peculiar e segundo o autor apenas nove das espécies referidas não as possuem, constituindo sua ausência caracter ao nível específico mais importante que sua presença. 


\section{Euphrosine aurantiaca Johnson, 1897}

Euphrosyne aurantiaca Johnson. 1897:157. est. Figs 1-4.- Kudenov, 1987: 187-189.

Corpo com 30-37 setígeros. Carúncula formada por dois lóbulos superpostos, coalescentes, sendo o superior mais longo e com a extremidade distal livre. Dois pares de olhos, o segundo no bordo anterior do prostômio. Antena mediana curta, inserida entre os olhos do primeiro par; antenas laterais também reduzidas, em posição frontal. Parapódios típicos do gênero. Brânquias arborescentes, com ramos subulados e subdivididos, em número de sete nos segmentos medianos; segundo cirro dorsal entre o terceiro e o quarto tronco branquial. Cerdas dorsais forqueadas e ringentes, estas últimas com ramos de largura aproximadamente igual; cerdas ventrais forqueadas, semelhantes às dorsais, porém mais longas e robustas.

Segundo JOHNSON (1897), o animal vivo é alaranjado, com uma faixa ventral mais escura. Nos exemplares fixados: amarelo-dourado.

Discussão. Euphrosine aurantiaca assemelha-se a E. triloba Ehlers, 1887, da qual se distingue principalmente pela carúncula com apenas dois lóbulos, superpostos e pela posição do segundo cirro dorsal entre a terceira e a quarta brânquia. Também difere pela forma não espatulada das cerdas ringentes e pelas cerdas ventrais mais robustas que as dorsais; condição inversa a encontrada em triloba.

Material examinado. Dois exemplares, com 18 e $20 \mathrm{~mm}$ de comprimento, coletados em Pernambuco e Alagoas, em conglomerados de algas calcárias (ZUEC-48PB).

Distribuição. Os espécimens de Johnson foram coletados na costa da Califórnia (San Pedro e Monterey); sua ocorrência na costa brasileira (Nordeste) é assinalada pela primeira vez.

\section{Euphrosine triloba Ehlers, 1887}

Figs $45-50$

Euphrosyne triloba Ehlers, 1887:31-33, est. 4.- Treadwell, 1939:179-180, Fig. 12.- Kudenov. 1987:187-189.- Uebelacker \& Johnson, 1984:38-6, Figs 38-3, 4a-e.

Corpo ovalado, com cerca de 28 setígeros; geralmente de pequeno porte, não ultrapassando $25 \mathrm{~mm}$ de comprimento. Carúncula trilobada, com ramos isolados e aproximadamente cilíndricos; o mediano mais longo alcançando o quinto setígero (Fig. 45). Olhos fortemente pigmentados, o par ventral parcialmente oculto pelo bordo dos primeiros segmentos (Fig. 46), antenas subuladas, as anteriores curtas, cirriformes, a mediana, com base cilíndrica volumosa, inserida entre os olhos, à frente da carúncula. Parapódios quase-coalescentes sobre o dorso; sete a oito troncos brânquiais, com ramificação dicotômica; dois cirros dorsais, longos e cilíndricos, o primeiro junto à base da primeira brânquia e o segundo entre a segunda e terceira; cirro ventral subulado (Fig. 47). Cerdas dispostas em fileiras contínuas interpenetradas; as dorsais, correspondendo ao notopódio, de dois tipos distintos: forqueadas, com ramos assimétricos, robustas e projetando-se 


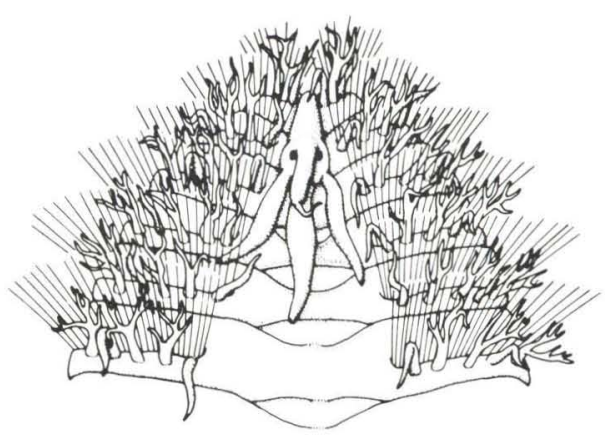

45
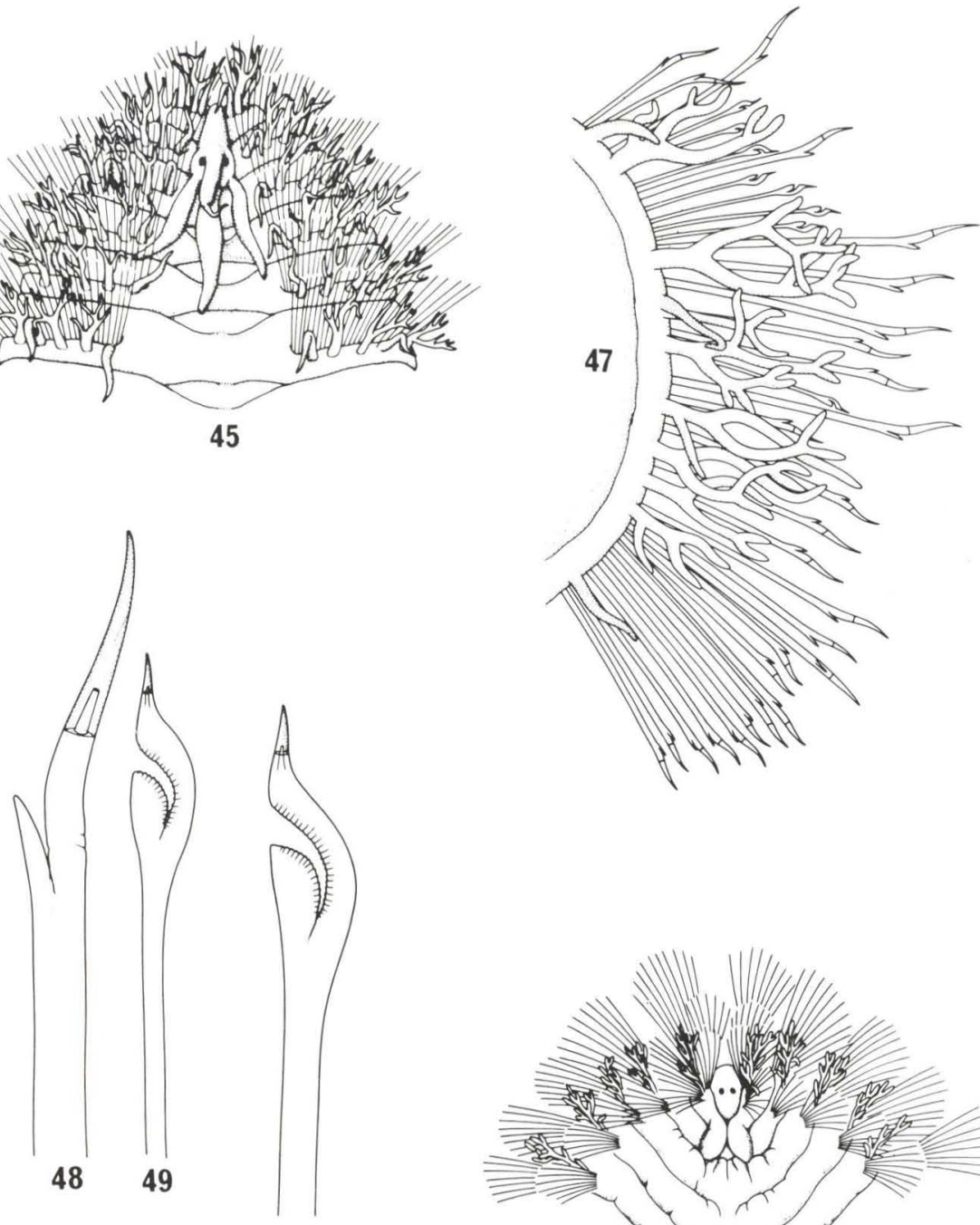

50

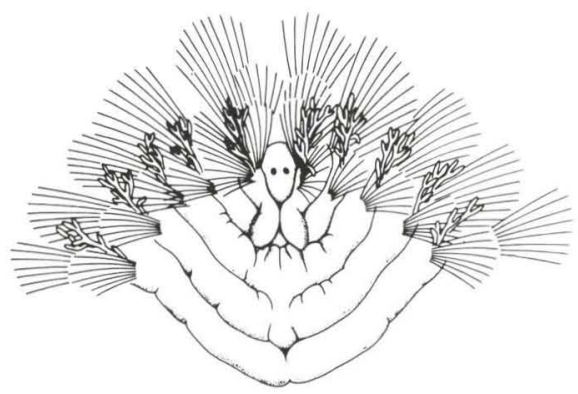

46

Figs 45-50. Euphrosine triloba Ehlers. (45) Região anterior, vista dorsal; (46) região anterior, vista ventral; (47) parapódio mediano; (48) cerda forqueada, do feixe notopodial; (49) cerda ringente, do feixe superior; (50) cerda ringente, do feixe mediano.

bem acima das demais (Fig. 48) e cerdas de forma singular, ringentes, também bífidas, mais curtas e delgadas, com ramos sulcados ou denticulados no bordo interno (Figs 49 e 50); ambas com haste oca e ápice do ramo maior, sólido. Cerdas ventrais de um único tipo, semelhantes às forqueadas, porém mais delgadas e sem 
o ápice característico das dorsais. Apêndices anais conspícuos.

Cor dos exemplares, fixados: pardo-amarelado, uniforme; cerdas vítreas, incolores.

Discussão. Euphrosine triloba Ehlers se assemelha a E. aurantiaca Johnson, 1887, distinguindo-se desta pela carúncula trilobada, pela posição do segundo cirro dorsal ("cirro lateral" de JOHNSON) que em aurantiaca fica entre a terceira e a quarta brânquia e, ainda, pela forma das cerdas ringentes fortemente espatuladas,

Nos exemplares examinados, tanto a forma das cerdas ringentes quanto a forma e distribuição das brânquias são idênticas às do tipo de EHLERS (1887). O aspecto peculiar do ápice das cerdas dorsais, figurado pelo autor também coincide; apenas não constatamos em nosso material a impregnação calcária mencionada por EHLERS (1887).

Material examinado. Três exemplares completos (ZUEC-49PB) o maior dos quais medindo $20 \mathrm{~mm}$, com 27 setígeros, provenientes da Ilha Grande (Rio de Janeiro) e São Sebastião (São Paulo); em fundos de areia lodosa.

Distribuição. Descrita da Flórida, a espécie foi reencontrada em Porto Rico - por TReadwell (1901) que a redescreveu em 1939. Com as ocorrências aqui referidas, sua distribuição é ampliada até a costa sudeste do Brasil.

AGRADECIMENTOS. À Fundação de Amparoà Pesquisa do Estado de São Paulo- FAPESP (Proc. biológicas 80/0395) e ao Conselho Nacional de Desenvolvimento Científico e Tecnológico CNPq (Proc. 40-2897/79) os autores agradecem os auxilios recebidos. A Toyomi Naruto pela confecção dos desenhos.

\section{REFERÊNCIAS BIBLIOGRÁFICAS}

AiYAR, R.G. \& K.H. Alikunhi. 1940. One new pisionid from the sandy beach, Madras. Rec. Indian Mus. Calcutta 42: 89-107.

1943. Change of the generic name Pisionella Aiyar \& Alikunhi, 1940 into Pisionidens (Polychaeta). Current Science, Bangalore, 12 (4): 120.

Audouin, J.V. \& H. Milne-Edwards. 1830. Description de l'Hipponoé, nouveau genre d'Annélides. Ann. Sci. Nat., Paris, 20 (1): 156-159.

. 1833. Classification des Annélides, et description de celles qui habitent les côtes de la France. Ann. Sci. Nat., Paris, 28 (1): 187-247.

Augener, H. 1913. Die Fauna Südwest-Australiens. Polychaeta errantia. Herausgegeben von Michaelsen und Hartmeyer, Jena, 4: 65-304.

DAY, J.H. 1967. A monograph on the Polychaeta of Southern Africa. Part 1 Errantia. Brit. Mus. Nat. Hist. Publ., London, 458p.

EHLERS, E. 1887. Report on the annelids of the dredging expedition of the U.S. Coast Survey Steamer Blake. Mus. Comp. Zool. Harvard Mem. 15: 1-335. 1901. Die polychaeten des magellanischen und chilenischen Strandes. Ein faunistischer Versuch. Festschr. K. Ges. Wiss. Göttingen, Math. Phys., $232 \mathrm{p}$. 
Fauchald, K. 1977a. The Polychaete worms. Definitions and keys to the Orders, Families and Genera. Los Angeles County, Mus. Nat. Hist., Sci. Ser., 28: $1-190$.

1977b. Polychaetes from intertidal areas in Panama, with a review of previous shallow-water records. Smiths. Contr. Zool. 221: 1-81.

Fauvel, P. 1923. Polychètes errantes. Fauna de France, Paris, 5: 1-488.

. 1932. Annelida polychaeta of the Indian Museum, Calcutta Indian Mus.

Calcutta Mem. 12 (1): 1-262.

1953. Annelida Polychaeta. The fauna of India including Pakistan, Ceylon, Burna and Malaya. Allahabad, The Indian Press, 507p.

Fauvel, P. \& F. Rullier. 1957. Nouvelle contribution à la faune des annélides polychètes du Sénégal. Bull. Inst. fr. Afr. noire, 19, Sér. A: 1: 24-96; 2: 373-399.

FRIEDRICH, H. 1956. Mitteilungen über neue und wenig bekannte Polychaeten aus Mittel - und Südamerika. Senkenbergiana Biologica 37: 57-58.

Gathof, J.M. 1984. Family Chrysopetalidae Ehlers, 1864. In: J.M. UEBELACKER \& P.G. Johnson (eds). Taxonomic Guide to the Polychaeta of the Northern Gulf of Mexico. Barry A. Vittor \& Associates. Mobile, 3, cap. 26, p. 1-10. Gardiner, S.L. 1975. Errant Polychaete annelids from North Carolina. Elisha Mitchell Sci. Soc. Journ 91 (3): 77-220.

GruBE, A.E. 1860. Beitrag: Zahlreiche Gattungen. 26, p. 71-118.

Grube, E. 1868. Ueber neue Anneliden. Schles. Gesells. Breslau. Jahresber. 45: $50-52$.

Hansen, A. 1882. Recherches sur les Annélides recueillies par M. le Professeur Edouard Van Beneden pendant son voyage au Brèsil et à la Plata. Mém. Cour. Acad. Roy. Sci. Belgique 44 (3): 1-29.

Hartman, O. 1951. The littoral marine annelids of the Gulf of Mexico. Publs. Inst. mar. Sci. Univ. Texas 2: 7-127.

1959. Catalogue of the polychaetous annelids of the world. Allan Hancock Fdn. Publ. Occ. Paper 23: 1-628.

. 1961. Polychaetous annelids from California. Allan Hancock Pacif. Exped. 25, p. 1-126.

.1968. Atlas of the errantiate polychaetous annelids from California. Los Angeles, Allan Hancock Found., Univ. South. California, 828p.

Hartmann-Schroeder, G. 1970. Zur Kenntnis der Pisionidae Süd-afrikas, mit Hinweisen auf die Entwicklung der Genital-Organe. Abh. Verh. naturwiss. Ver. Hamburg 14: 55-70.

ImajImA, M. \& HaRTManN, O. 1964. The polychaetous annelids of Japan, Pt. 1. Allan Hancock Fdn. Occ. Paper 26: 1-237.

JOHNSON, H.P. 1897. A preliminary account of the marine annelids of the Pacific coast, with descriptions of the new species. Euphrosynidae, Amphinomidae, Palmyridae, Polynoidae and Sigalionidae. Proc. Calif. Acad. Sci. Zool. 1: 153-190.

KinberG, J.G.H. 1910. Kongliga Svenska Fregatten "Eugenies"Resa omkring 
jorden under befail af C.A. Virgin aren 1851-1853. Zoologi. 3. Annulater, $78 \mathrm{p}$.

KUDENOV, J.D. 1987. Review of the primary species characters for the genus Euphrosyne. Biol. Soc. Wash. Bull. 7: 184-193.

Lana, P.C. 1984. Anelídeos Poliquetos Errantes do Litoral do Estado do

Paraná. Tese de Doutorado, não publicada, Instituto Oceanográfico, Universidade de São Paulo, São Paulo, 275p.

LEVINSEN, G.M.R. 1887. Kara-Havets Ledorme (Annulata), p. 288-303. In: C.F. LÜTKEN (ed.). Dijmphna-Togtets Zoologisk-botaniske Udbytte. Kobenhavn, J. Hagerup.

MonRo, C.C.A. 1930. Polychaete worms. Discovery Reports 2: 1-222.

1933. The Polychaeta Sedentaria collected by Dr. C. Crossland at Colon

in the Panama region and the Galapagos Islands during the expedition of the S.Y. "St. George". Proc. zool. Soc. Lond. 1: 1-96.

Morgado, E.H. \& C.Z. Amaral. 1981. Anelideos poliquetos associados a um briozoário. II. Palmyridae. Bolm. Inst. oceanogr., São Paulo, 30 (1): 87-89.

NONATO, E.F. 1981. Contribuição ao conhecimento dos anelídeos poliquetas bentônicos da plataforma continental hrasileira entre Cabo Frio e o Arroio Chui. Tese de Livre-Docência, não publicada, Instituto Oceanográfico, Universidade de São Paulo, São Paulo, 246p.

Nonato, E.F. \& J.A.C. LunA. 1970. Anelídeos poliquetas do Nordeste do Brasil. I. Poliquetas bentônicos da costa de Alagoas e Sergipe. Bolm. Inst. oceanogr., São Paulo, 19: 57-130.

ORENZANZ, J.M. 1972. Los anelideos poliquetos de la provincia biogeografica Argentina. I. Palmyridae (=Chrysopetalidae), Amphinomidae y Euphrosynidae. Physis, Sec. A, Buenos Aires, 31 (83): 485-501.

Orensanz, J.M. \& GianuCA, N.M. 1974. Contribuição ao conhecimento dos anelídeos poliquetas do Rio Grande do Sul, Brasil. I. Lista sistemática preliminar e descrição de tres novas espécies. Comun. Mus. Ci. PUCRGS, Porto Alegre, 4: 1-37.

PERKINS, TH.H. 1985. Chrysopetalum, Bawania and two new genera of Chrysopetalidae, principally from Florida. Proc. Biol. Soc. Wash. 98 (4): 856-915.

Peters, W.C.H. 1854. Naturwissenschaftliche Reise nach Mosambique in 1842 bis 1848 ausgeführt. Akad. wiss. Berlin Monatsber., p. 610-614.

Pettibone, M.H. 1963. Marine Polychaete Worms of the New England Region. 1. Aphroditidae through Trochochaetidae. U.S. Nat. Mus. Bull. 227: 1-356. Quatrefages, A. 1865. Note sur la classification des annélides. Acad. Sci. nat., Paris, 5 (3): 253-296.

Rullier, F. 1964. Résultats scientifiques des campagnes de la "Calypso". Iles du Cap Vert. Annélides polychètes. Ann. Inst. océanogr., Monaco, 41 (6): 113-218.

Rullier, F. \& L. Amoureux. 1979. Annélides polychètes. Campagne de la "Calypso" au large des côtes atlantiques de l'Amerique du Sud (33). Ann. Inst. 
océanogr. 55 (supl.): 145-206.

Salazar-Vallejo, S.I. 1992. Dos Nuevos Registros de Anfínómidos (Polychaeta: Amphinomidae) para el Mar Caribe, con Notas Descriptivas para Ambas Espécies. Caribbean Journal of Science 28 (3-4): 216-217.

SCHMARDA, L.K. 1861. Neue wirbelose Thiere beobachtet und gesammelt auf einer Reise um die Erde 1853 bis 1857, Turbellarien, Rotatorien und Anneliden, 2. Leipzig, W. Engelmann., 164p.

SIEWING, R. 1954 - Zur Verbreitung von Pisionidens indica Aiyar \& Alikunhi.

Kieler Meeresforsch. 10 (1): 81-83.

Southern, R. 1914. Archiannelida and Polychaeta. In: Clare Island Survey, pt.

47. Roy. Irish Acad. Dublin Proc. 31 (47): 1-160.

Temperini, M.T. 1981. Sistemática e Distribuição dos Poliquetos Errantes da

Plataforma Continental Brasileira entre as Latitudes de $23^{\circ} 05^{\prime} \mathrm{S}$ e $30^{\circ} 00^{\prime} \mathrm{S}$.

Dissertação de Mestrado, não publicada, Instituto Oceanográfico Universidade de São Paulo, São Paulo, 89p.

TEBBLE, N. 1953 - On a new and aberrant marine annelid from Natal, South Africa.

Ann. Mag. Nat. Hist. 6: 937-944.

Treadwell, A.L. 1901. The polychaetous annelids of Porto Rico. Bull. U.S.

Fish Comm. for 1900 20: 181-210.

1939. Polychaetous annelids of Porto Rico and vincinity. Scientific

Survey of Porto Rico and the Virgin Islands. Acad. Sci., New York, 16 (2): 151-319.

Ushakov, P.V. 1955. Polychaeta of far eastern seas of the U.S.S.R. Akad.

Nauk U.S.S.R, 445p. (em russo; traduzido para o inglês pelo Israel Program for Scientific Translations, Jerusalém, 1965: 1-419).

Uebelacker, J.M. \& P.G. Johnson. 1984. Taxonomic Guide to the Polychaetes of the Northern Gulf of Mexico. Alabama, Barry A. Vittor \& Associates Inc., vols. 3 e 5.

Webster, H.E. 1884. Annelida from Bermuda. Bull. U.S. natn. Mus. 25 : 305-327.

WestheIDE, W. 1970. Zur Organisation, Biologie und Oekologie des interstitiellen Polychaeten Hesionides gohari Hartman-Schröder (Hesionidae). Mikrofauna Meeresboden 3: 1-37.

Westhelde, W. 1974. Interstitielle Polychaeten aus brasilianischen Sandstränden. Mikrofauna Meeresboden 31: 1-16.

Recebido em 10.IV.1994; aceito em 13.VII.1994. 